\title{
Electromagnetic Monitoring of Miyake-jima Volcano, Izu-Bonin Arc, Japan: A Preliminary Report
}

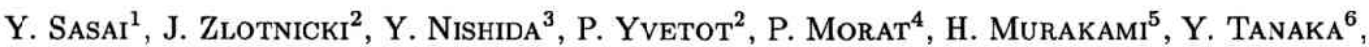 \\ Y. IsHIKAWA ${ }^{1}, \mathrm{~S}$. KoYAMA ${ }^{1}$, and W. SeKIGUCHI ${ }^{1}$ \\ ${ }^{1}$ Earthquake Research Institute, The University of Tokyo, Bunkyo-ku, Tokyo 113, Japan \\ ${ }^{2}$ Laboratoire de Geophysique d'Orleans, Orleans 45071, Cedex 02, France \\ ${ }^{3}$ Graduate School of Science, Hokkaido University, Sapporo 060, Japan \\ ${ }^{4}$ Institut de Physique du Globe de Paris, Paris 75252, Cedex 05, France \\ ${ }^{5}$ Faculty of Science, Kochi University, Kochi 780, Japan \\ ${ }^{6}$ Geophysical Research Laboratory, Fac. Sci., Kyoto University, Beppu 874, Japan
}

(Received November 11, 1996; Revised June 27, 1997; Accepted August 29, 1997)

\begin{abstract}
Miyake-jima Island, about $150 \mathrm{~km}$ south of Tokyo in Izu-Bonin Arc, is one of the most active basalt volcanoes in Japan. Big eruptions took place in 1940, 1962 and 1983 . In this volcano, magma ascends towards a depth of a few $\mathrm{km}$ below the summit without any significant earthquakes or deformation, then gives rise to flank fissure eruptions because of the blockaded vent just beneath the summit crater. Hence eruption forecasts are very difficult to make with mechanical methods (i.e., seismic and deformation measurements) alone. We have developed an electromagnetic monitoring system of the volcano that combines magnetic, resistivity and electric field (SP) measurements. We expect that magma injection and the hydrothermal materials dispatched from it will result in thermal demagnetization, resistivity change and SP variations together with the electrokinetic-magnetic effect. Since October, 1995, we have continuously operated eight well distributed proton magnetometers over the island as well as two SP measurement systems on the NE and SW fissure zones. SP surveys brought to light distinct anomalies, which strongly suggest a close relation to the eruption mechanism. They are a positive anomaly up to $700 \mathrm{mV}$ centered around the summit, and two negative ones amounting to $-250 \mathrm{mV}$ on the north and $-100 \mathrm{mV}$ on the southwestern mountainside. These anomalies can originate from a common mechanism: Rainwater penetrates from fissure zones along fractures toward the center of the volcano, a few $\mathrm{km}$ deep, where it is warmed by the heat supplied from deep-seated magma to rise through the summit vent. The down flow makes the negative, while the upwelling the positive SP anomalies, respectively. Miyake-jima island is located near the path of the Kuroshio, the most dominant ocean current in the western Pacific. A large magnetic variation amounting to several $\mathrm{nT}$ was observed to result from the meander of the flow path. This phenomenon produces serious EM noise and complicates monitoring for volcanic activity. It is crucial to investigate the characteristics of motionally-induced EM fields and to properly eliminate their effects.
\end{abstract}

\section{Introduction}

Miyake-jima volcano belongs to the Izu-Bonin Arc along the eastern margin of the Phillipine Sea Plate (Fig. 1). It is one of the most active basaltic stratovolcanoes in Japan. In the last millenium, at least 14 eruptions have been recorded (Isshiki, 1964). During this century, it erupted very regularly, i.e. in 1940, 1962 and 1983. If the present supply rate of magma remains uniform, we can expect activity early in the next century; we would say that we might be about 10 years prior to the next eruption. A typical eruption mode of the volcano is the flank fissure eruption (Isshiki, 1964), which is very difficult to forecast when and where. To find an effective way of monitoring and, if possible, how to issue an alarm is an urgent objective for this volcano. 


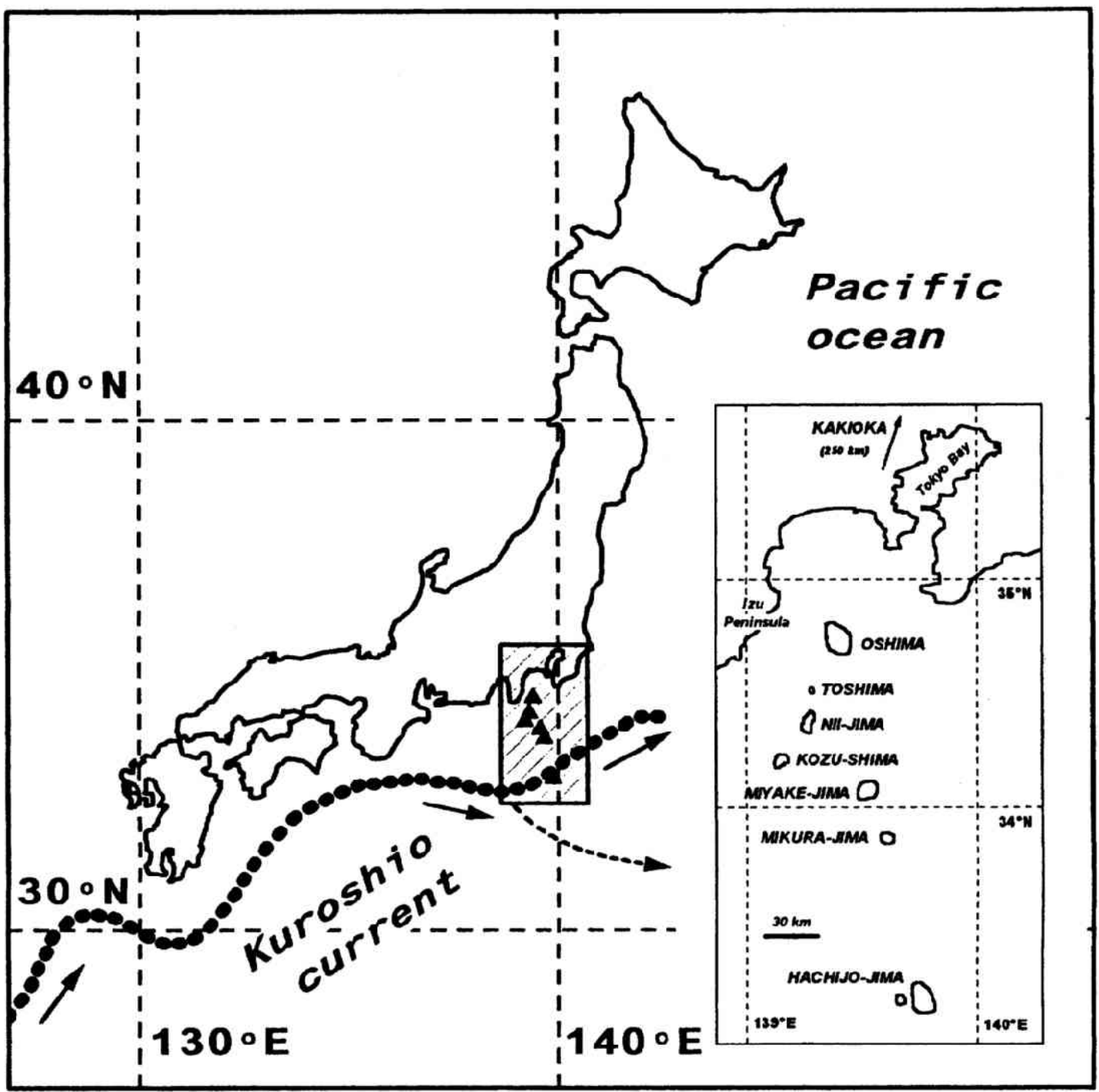

Fig. 1. Map showing the location of the northernmost part of Izu-Bonin Arc (the hatched area). The included map shows the locations of Miyake-jima, Hachijo-jima and other volcanic islands. Kakioka Magnetic Observatory (KAK) is located $250 \mathrm{~km}$ north of Miyake-jima. Also depicted in the large map is a typical flow-path of the Kuroshio current when flowing smoothly from west to east.

In the 1940 activity, the fissure eruption occurred on the northeastern flank and then was followed by a summit eruption (Tsuya, 1941). Modern geophysical observations were first introduced for this event, i.e. seismic observations, triangulation, magnetic and electric measurements. In particular, big magnetic changes were reported by several authors (Kato, 1940; Takahasi and Hirano, 1941a, b; Nagata, 1941; Minakami, 1941). Even continuous observation of electric field (Self Potential: SP) was attempted by Hagiwara (1941). Nagata's (1943) pioneer work on thermal remanent magnetization (TRM) was strongly motivated by his experiences on Miyake-jima. Hence the 1940 eruption of Miyake-jima volcano was epoch-making in the electromagnetic study 
of volcanoes.

The 1962 eruption was a typical flank fissure eruption, again on the northeastern slope. It was followed by severe swarm earthquakes but no subsequent eruption (Minakami, 1964). Kato and Muroi (1963) reported big changes in the geomagnetic dip during the period before and after the eruption. However, during the post-eruption period, Yukutake et al. (1963) did not observe big magnetic changes such as were reported for the 1940 event in their total intensity measurements with a proton precession magnetometer.

The activity in 1983 initiated with a fissure eruption on the southwestern flank including prominent phreatomagmatic explosions near the southern coast (Aramaki et al., 1986). In 1980, prior to the 1983 eruption, many joint cooperative observations of Miyake-jima volcano were carried out. These included seismic, leveling, gravity, electromagnetic, geothermal and geochemical measurements and investigations. Kawamura et al. (1982) established 18 repeat magnetic survey points of total intensity well distributed over the volcano. Yukutake et al. (1982) conducted a resistivity survey with the Schlumberger and ELF-VLF magnetotelluric methods.

Just after the 1983 eruption, all these points were resurveyed; significant changes in the total force intensity (Nakagawa et al., 1984) as well as in the resistivity (Utada et al., 1984) were observed in association with the eruption. During the four month period after the eruption, a few tens of $\mathrm{nT}$ changes in the total intensity were observed, which was ascribed to hydrothermal circulation within the volcano edifice (Nakagawa et al., 1984). Repeat surveys of ELF-VLF magnetotelluric measurement brought to light the growth of a hydrothermal acquifer just beneath the summit crater (Utada et al., 1984, 1986). All these observations provided us with important information on where magma was stored within the volcano during the eruption. Sasai et al. (1984) discussed the eruption mechanism in the case of the 1983 activity on the basis of electromagnetic data.

During the past decade after the 1983 Miyake-jima eruption, electromagnetic methods to monitor the volcanic activity have made steady progress in Japan. Total intensity measurements with an array of proton precession magnetometers detected some clearcut signals related to eruptions of the 1986 Izu-Oshima (Yukutake, 1990; Sasai et al., 1990), the 1989 Teishi Knoll (Izu) (Sasai and Ishikawa, 1991), the 1989-90 Aso (Tanaka, 1993) and the 1990-92 Unzen volcanoes (Tanaka, 1995). In particular, a most remarkable precursor was observed by controlled source resistivity measurement in Izu-Oshima volcano (Yukutake et al., 1987; Utada, 1991). With the aid of knowledge on the depth of acquifers, the ascent speed of the magma head was estimated as $5 \mathrm{~m} /$ day for Izu-Oshima (Electromagnetic Research Group of Izu-Oshima Volcano, 1988) and as $20 \mathrm{~m} /$ day for Unzen volcano (Kagiyama et al., 1995). A new-comer to EM observations was continuous measurement of the self potential (SP). Hashimoto and Tanaka (1995) observed changes in the self potential amounting to $1000 \mathrm{mV}$ associated with intrusion of dacite lava.

Within a volcano, where down-going water is reheated in the proximity of a magmatic complex, it gives rise to huge hydrothermal cells (Zablocki, 1976; Corwin and Hoover, 1979; Ballestracci and Nishida, 1987). The SP mapping presented good indication for fluid flow including meteoric water and hydrothermal materials within a volcano edifice. The physical basis for this may be the electrokinetic effect of the porous media flow (Nourbehecht, 1963; Ishido and Mizutani, 1981). Large self potential anomalies in volcanic and geothermal areas, sometimes more than several hundreds $\mathrm{mV}$, could be attributed to the electrokinetic effect, e.g., on Usu, Hokkaido Komaga-take and Me-akan (Nishida and Tomiya, 1987; Matsushima et al., 1990), la Soufriere (Zlotnicki et al., 1994a), Piton de la Fournaise (Zlotnicki et al., 1994b) and Unzen volcanoes (Hashimoto and Tanaka, 1995).

Some new aspects were introduced from observations on a very active hot-spot volcano, Piton de la Fournaise on Reunion Island (Indian Ocean, France). Electromagnetic measurements started in late 1985 on this volcano (Zlotnicki and Le Mouel, 1988). Remarkable volcanomagnetic effects observed on Piton de la Fournaise volcano were classified into three types (Zlotnicki et 
al., 1993): (a) long-term trend closely related to the growth and decline of volcanic activity, (b) annual variations along the main fracture zone, and (c) short-term changes associated with fissure eruptions. Some of them are difficult to explain by thermal-magnetic or piezomagnetic effects. Zlotnicki and Le Mouel (1990) proposed the electrokinetic origin due to the hydrothermal circulation within the volcano edifice.

Because of the potential importance of electrokinetic effects in volcanoes, measurements of self potential were carried out vigorously on Piton de la Fournaise(Zlotnicki et al., 1994b; Michel and Zlotnicki, 1995). Mapping of SP brought to light a semi-circular positive anomaly along the main fracture zone, the highest on the central cone, which may reflect the hydrothermal circulation system within the volcano. In particular, a transient variation up to more than 1200 $\mathrm{mV}$ appeared in association with the fissure eruption, which decayed one month later (Zlotnicki et al., 1994b). This was the first observation of such a phenomenon. Similar observations were later made on Unzen volcano (Hashimoto and Tanaka, 1995). Thus on Piton de la Fournaise volcano, predominant electromagnetic effects of various kinds associated with the volcanic activity have been observed, which are a match for the experiences during the recent ten years in Japan.

Since both Miyake-jima and Piton de la Fournaise are basaltic volcanoes, the behavior of magma ascent is very similar in each. In some cases on the Fournaise volcano, a fissure eruption begins suddenly with earthquakes, tremors and ground deformation after a long quiescense (Delorme et al., 1989). Quite similarly on Miyake-jima volcano, earthquakes were felt in the final few hours preceding the initial explosive eruptions for the recent three activities in 1940, 1962 and 1983 (Tsuya, 1941; Minakami, 1964; Aramaki et al., 1986). It is an urgent problem to identify other precursory phenomena to prepare for such a surprise attack. Hence we have much to learn from Piton de la Fournaise when designing the monitoring system of Miyake-jima volcano.

We selected Miyake-jima and Piton de la Fournaise volcanoes as our common test field sites for volcano-electromagnetic study under the Japan-France cooperation project. We would emphasize that we combine three kinds of EM measurements, i.e. magnetic field, resistivity and $\mathrm{SP}$, to further develop a unified model to interpret all the data. This is because, in the past, the three kinds of measurements were analysed rather independently with each other. However, since the different observations reflect the same identical source, i.e. magma and hydrothermal materials dispatched from it, detection of the existence of the source can be made with less ambiguity by using the three kinds of data. Forecasting the volcanic activity should be possible by combining such well-determined EM data with other information from geophysical and geochemical data.

We started our cooperative observations in October, 1995. We have already given two brief reports describing our observation system and some of the preliminary survey results (Nishida et al., 1996; Sasai et al., 1996). In this paper, we will present results of continuous observations of geomagnetic total intensity and self potential together with the compiled data of SP mapping on Miyake-jima volcano. In particular, continuous electric and magnetic field data are strongly affected by the motionally-induced EM fields due to variations of the Kuroshio ocean current. This phenomenon is an interesting subject in the electromagnetic induction study of the earth.

\section{Monitoring the Activity of Miyake-jima Volcano by Electromagnetic Method}

We summarize discussion of the eruption mechanism of Miyake-jima volcano in the Appendix. Due to the lack of dense monitoring networks, we can only give a speculative interpretation of the eruptions mechanism. Apparently, deep intrusions are injected to depths of 3 to $2 \mathrm{~km}$ below the sea level and then stop. This generates magnetic field changes due to thermal demagnetization as well as changes in the resistivity at this depth. Fresh magma strongly disturbs the hydrothermal system and generates felt earthquakes. The mechanical weakness axis trending North-East/South-West, due to the previous eruptions, should initially be activated and would give rise to explosive fissural vents. In Fig. 2 is shown the location of continuously recording 


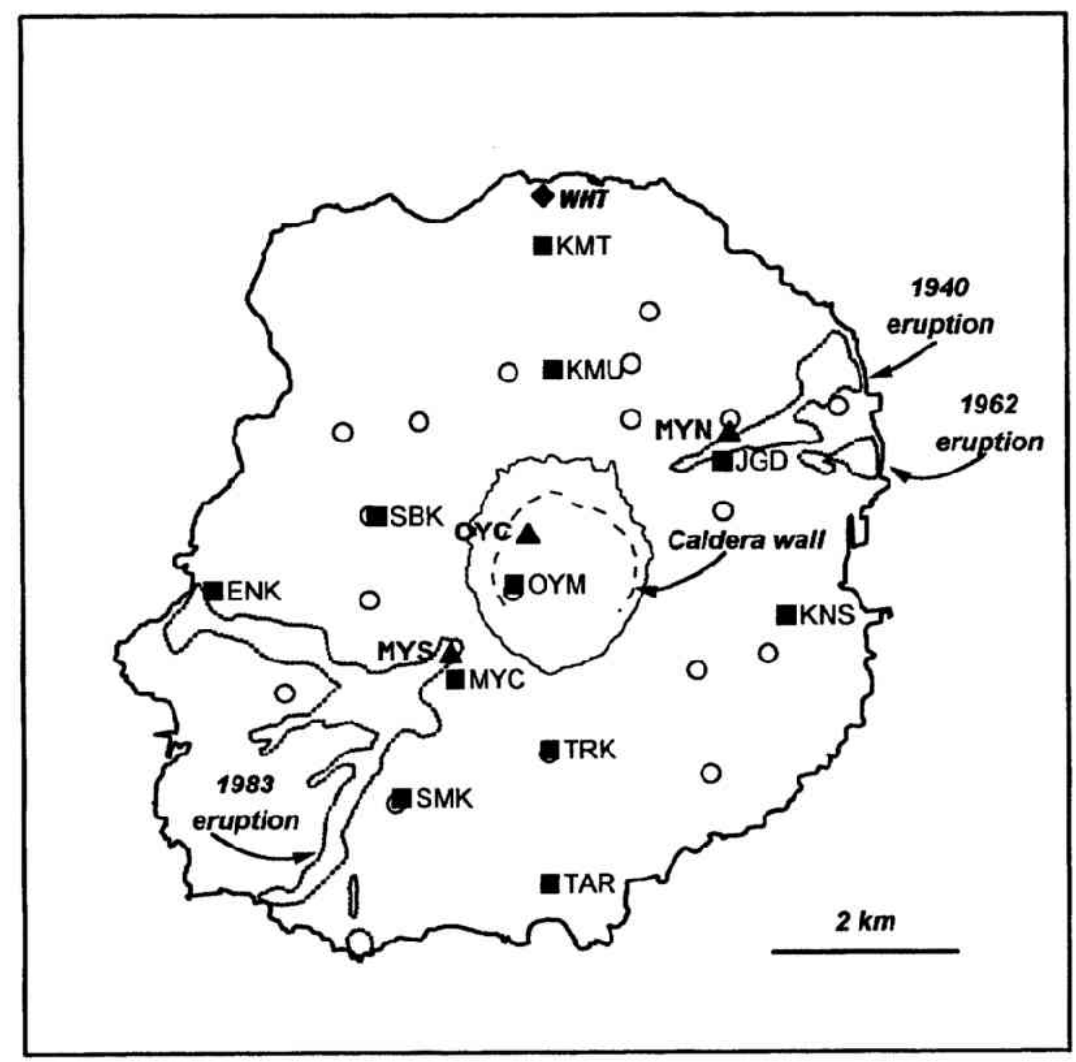

Fig. 2. Locations of electromagnetic observation stations on Miyake-jima island. Squares: Proton precession magnetometers. Triangles: Continuous SP measurement sites. OYC is the continuous MT measurements site established in the summer of 1996. Circles: Repeat magnetic survey points since 1980. WHT at the northern tip is the Miyake-jima weather station (JMA). Fissures zones and lava flows at the time of 1940, 1962 and 1983 eruptions, are shown, together with the summit caldera rim.

proton precession magnetometers and SP stations. The key point concerns how to detect magma as it rises up toward a depth of 2-3 km. Some proton magnetometers near the coast line target this depth. In order to monitor possible interaction between an injection of a new magma batch in the upper part of Miyake-jima volcano and the hydrothermal system, we installed a continuous monitoring network of the Self Potential on both North-East and South-West flanks.

The proton magnetometer data at MYC is telemetered to the Earthquake Research Institute (ERI), the University of Tokyo. This station is used as a reference station on Miyake-jima volcano. All the other proton magnetometers are installed as follows: A sensor is mounted on a $2.5 \mathrm{~m}$ high vinyl chloride tube with $15 \mathrm{~cm}$ diameter and KM62 type proton magnetometer with an accuracy of $0.1 \mathrm{nT}$ is used (Tanaka, 1993). At each station, electric power is supplied by solar pannels. In Fig. 2 repeat survey points established by Kawamura et al. (1982) are also shown. We took into account the following conditions in selecting the continuous observation sites: (1) We put the continuously recording magnetometers near some survey points which have provided us with important information for post-eruption process after the 1983 activity, such as SBK, OYM and TRK. (2) Near the coastline, we established four stations KMT, KNS, TAR and ENK. It is partly for investigation of the island effect on short-period geomagnetic variations. (3) The north-south 
alignment of magnetometers, i.e. KMT, KMU, OYM, TRK and TAR, aims at detecting possible changes at a depth of a few $\mathrm{km}$ beneath the summit crater.

One of our purposes is to investigate the characteristics of natural electromagnetic "noises" such as spatial discrepancy of geomagnetic short-period disturbances due to the island effect and motionally induced EM fields by ocean tides and currents. This enables us to eliminate apparent variations in the past repeat surveys as well as to reproduce the accurate volcanomagnetic effects over the entire reccurrence cycle of eruptions since 1983. The other is to search for the deep electrical conductivity structure by making use of total intensity data. The time-varying external field of ionospheric and magnetospheric origin induces electric currents in the conducting ocean. The electric currents are deflected away by a resistive island, which produces locally different magnetic field, especially in its vertical component, i.e. the island effect (Sasai, 1967, 1968). The island effect on Miyake-jima island was investigated in detail by Honkura (1971). He presented a deep conductivity profile beneath the island by using the frequency dependence of the island effect (Honkura, 1973). The proton magnetometer can be used as a one-component variometer which has complete stability for measurement of long-period magnetic variations.

The continuously recording SP measurement stations were established at MYN on the northeastern and at MYS on the southwestern fissure zone, respectively. 8 channels of data are recorded with a sampling interval of one minute. Details of measurement system will be given in Section 4 . From the results in Piton de la Fournaise volcano (Zlotnicki et al., 1994b), we suppose that SP values on both the fissure zones should be most sensitive to any changes in the hydrothermal system possibly caused by magma ascent. Our presumption was supported by a portable SP survey conducted in October, 1995 and in April, 1996. These results will be presented in Section 5.

On Piton de la Founaise volcano, a big annual variation of geomagnetic total intensity $(>20$ $\mathrm{nT}$ ) was found along the main fracture zone. It has been ascribed to the electrokinetic-magnetic effect (Zlotnicki and Le Mouel, 1990). Hence we installed the proton magnetometer station JGD near MYN SP station and SMK near MYS, respectively. We intend to begin magnetic observations at JGD and SMK in the near future.

We installed the SP measurement stations and the sensors of proton precession magnetometer in October, 1995. Continuous measurements of SP at MYN and MYS, and magnetic observations at MYC, KMT and TAR began in October, 1995. Later on we started magnetic observations at KMU, OYM, KNS, ENK and TRK successively. Preliminary results of magnetic and SP observations will be given in the following sections.

\section{Continuous Observations of the Magnetic Total Force Intensity}

Figure 3 shows the whole-day mean simple differences of the total intensity between each station on Miyake-jima island and HJJ during the period from October 1995 to June 1996. The reference station HJJ (Hydrographic Office, Japan Maritime Safety Agency) is located at the southernmost tip of Hachijo-jima island, about $110 \mathrm{~km}$ south of Miyake-jima (see Fig. 1). At stations KMT, MYC and TAR, we find that the total intensity began to decrease rather rapidly since the middle of November; it decreased to the minimum in December and gradually recovered until March 1996. At the other stations, the variations of the total intensity are very similar, where observations started in November or December. These slow variations are supposed to be caused by the motionally induced magnetic field produced by the Kuroshio current, a most dominant ocean flow in the western Pacific. Ueda et al. (1986) reported that HJJ station is much affected by the Kuroshio current. We will discuss it later in this section.

Another kind of motionally induced magnetic field is involved in the total intensity data on Miyake-jima. Figure 4 shows plots of the night-time $(00 \mathrm{~h} 00 \mathrm{~m}-04 \mathrm{~h} 59 \mathrm{~m}$ LT) daily mean differenced data on Miyake-jima relative to MYC on the same island. They are shown only for the period from October 1995 till March 1996, because MYC suffered some instrumental troubles owing 


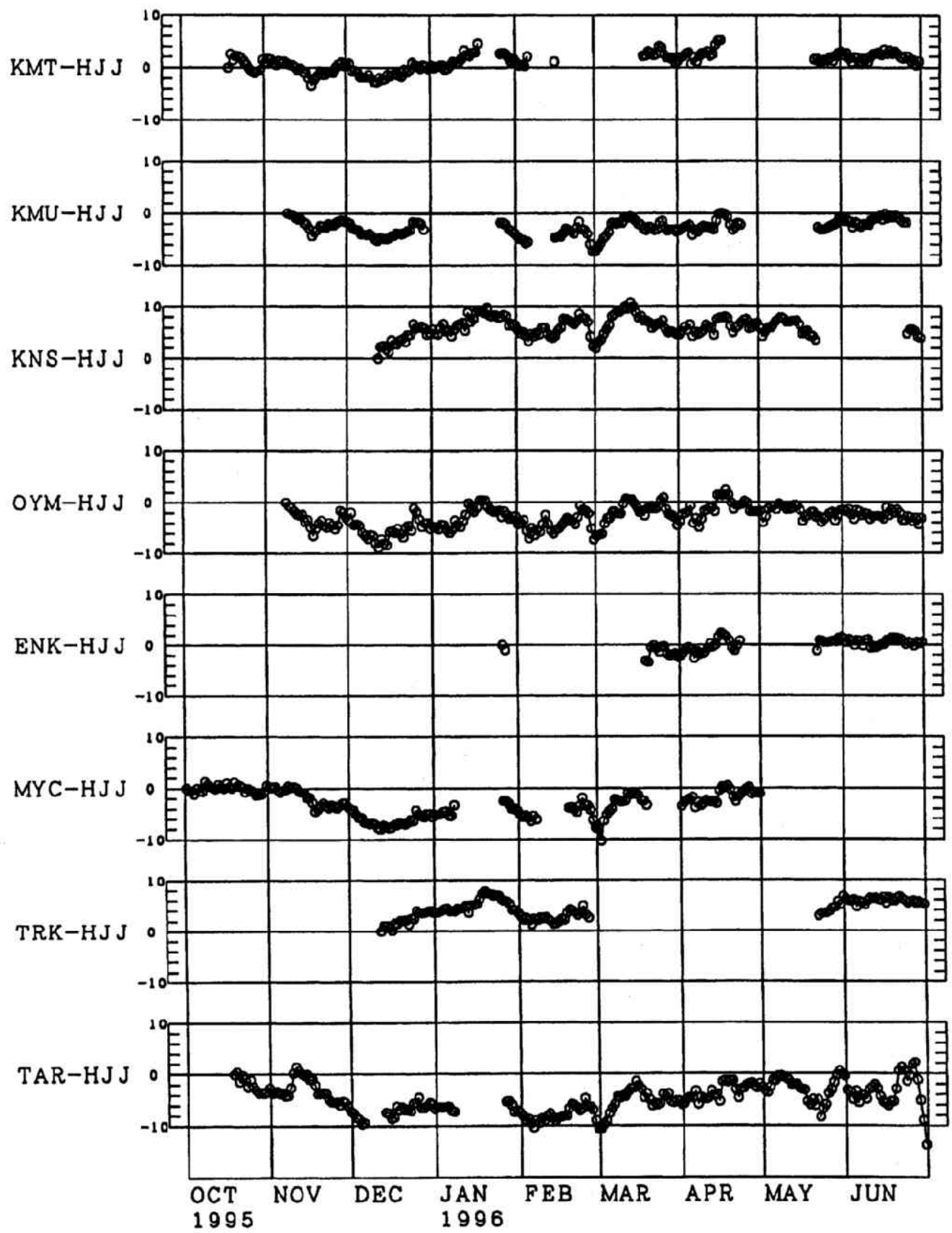

Fig. 3. The whole-day daily mean simple differences of the total force intensity between each station on Miyake-jima and HJJ during the period from October 1995 to June 1996. Unit in the ordinate is in nT.

to lightning. At some stations, we find that oscillatory variations with half a month period dominantly appear from October to December and that they fade away after February. This variation is an apparent one due to aliasing caused by discrete sampling (i.e. averaging only night-time data) of tidal induced magnetic field. Since the period of aliased wave is almost half a 


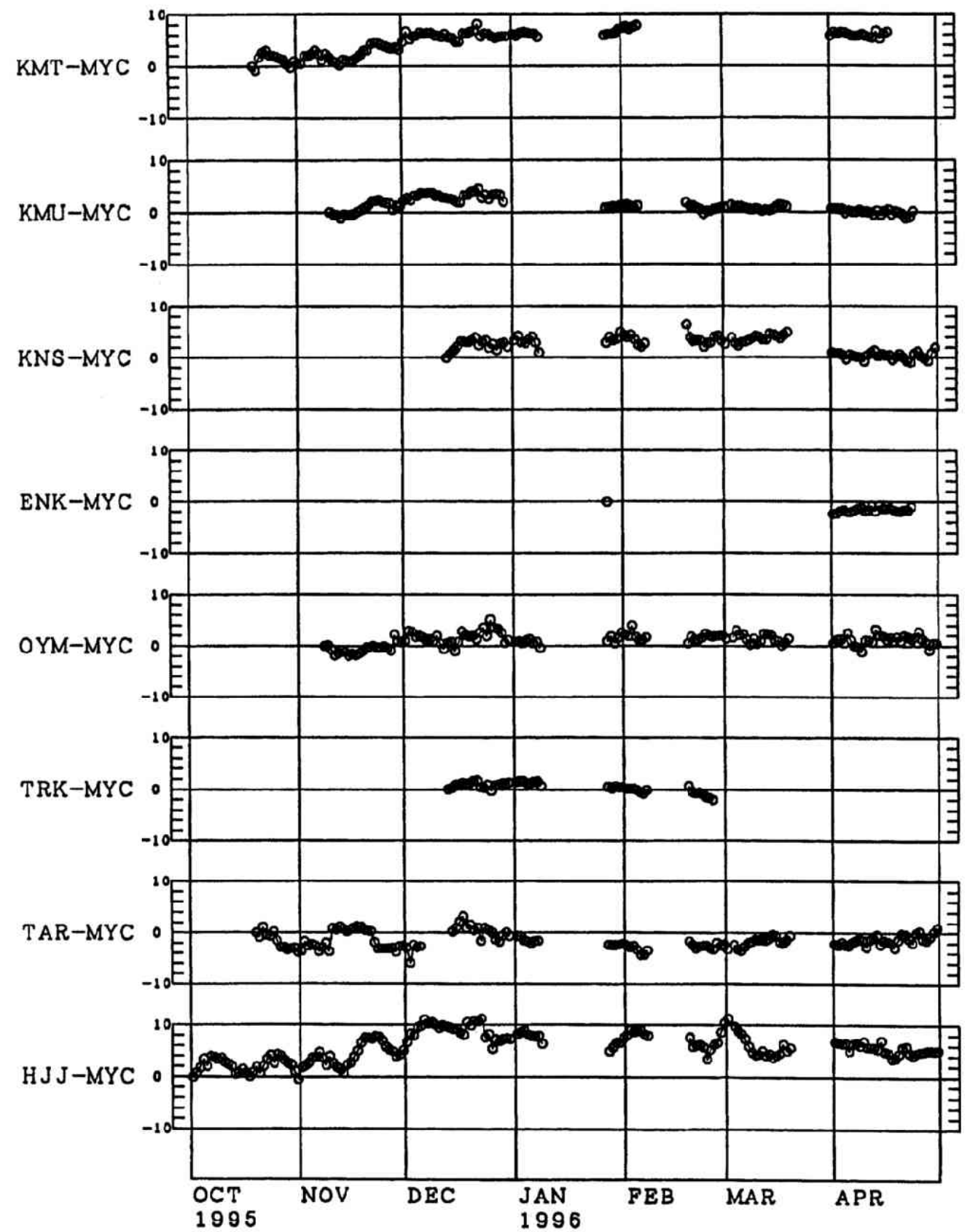

Fig. 4. The night-time (00h00m-04h59m JST) daily mean simple differences of the total force intensity between each station on Miyake-jima and MYC during the same period. Unit in the ordinate is in nT.

month, the main constituent of the tidal field should be $\mathrm{M}_{2}$ (lunar semi-diurnal period) component (Sasai and Ishikawa, 1985). Fortunately, the tidal induced magnetic fields are almost completely suppressed by averaging minutely values over a day.

The day-to-day fluctuations in the simple difference curves in Fig. 3 are mostly due to local 
electromagnetic induction effect, or the island effect. We notice a strange behavior of the total intensity changes at TAR in November 1995 as shown in Figs. 3 and 4. Such a step-like offset makes us suspect of any artificial disturbance. However, we could not find any evidence. Moreover, this anomalous change happened just when the meander of the Kuroshio current started. TAR station is located on the southern tip of the island, close to an old crater lake, which suggests a very complicated resistivity structure beneath it. We remain it as a future subject to elucidate the cause of this possible magnetic event, if any. Both the reference stations HJJ and MYC are severely contaminated by the motionally induced magnetic field. We choose KAK (Kakioka Magnetic Observatory, JMA) as a reference station not influenced by the oceanic currents. KAK is located about $250 \mathrm{~km}$ north of Miyake-jima, on the mainland (Fig. 1). However, this distance is another cause of apparent variations in the total intensity differences among stations in Miyakejima island and KAK. Owing to the discrepancy in the phase and amplitude of the daily variation, the minutely simple difference curve between Miyake-jima and KAK has the deviation of up to $10 \mathrm{nT}$ or more during the day-time.

We usually use a simple algorithm to automatically discard some unusual values in field observations, in which we assume that simple differences between a station pair do not exceed a certain threshold value (usually a few to $10 \mathrm{nT}$ ). This method of computation is not applicable to a pair of stations with a large phase lag in the time variations. Hence we computed the daily mean simple differences betweeen a station in Miyake-jima and KAK on the basis of the following formula:

$$
\overline{\Delta F_{\mathrm{MYK}-\mathrm{KAK}}}=\overline{\Delta F_{\mathrm{MYK}-\mathrm{HJJ}}}+\overline{\left\langle\Delta F_{\mathrm{HJJ}-\mathrm{KAK}}\right\rangle}
$$

where MYK indicates a station in Miyake-jima island. The first term on the right-hand side of Eq. (1) is the whole-day mean simple differences between MYK and HJJ using the algorithm for automatic noise elimination. We can apply this method to the station pair between MYK and HJJ, of which results have already been given in Fig. 3. The second term is the daily mean of simple differences between HJJ and KAK using every minutes data on each day. Both the observatories provide us with a complete set of 4 components data with good quality.

Figure 5 shows daily mean values of simple differences in the total intensity between each station on Miyake-jima and KAK according to Eq. (1). At the bottom is given the daily mean difference between HJJ and KAK, i.e. the second term on the right-hand side of Eq. (1). We find that at four stations, i.e., KMT, MYC, TAR and HJJ, the total intensity increases rather rapidly in the middle of November 1995, reaches its peak in December and then decreases toward March 1996. As will be briefly described in the next section, drastic changes in the flow path of the Kuroshio current took place during the period (see Fig. 7 in Section 4). It flowed almost straight from WSW to ENE direction in October, 1995, but suddenly began to meander in November and to recover a West-East flow in March, 1996. The total intensity at the above four stations was much disturbed in November and December, when the main stream around Miyake-jima and Hachijo-jima islands was from South to North.

The movement of conducting sea water under the earth's magnetic field produces the electric current $\mathbf{i}=\sigma\left(\mathbf{v} \times \mathbf{B}_{\mathbf{0}}\right) . \sigma$ is the electric conductivity of sea water, $\mathbf{v}$ the velocity vector of the ocean flow and $\mathbf{B}_{\mathbf{0}}$ the main geomagnetic field vector, respectively. Westward horizontal electric currents are induced by northward ocean current flow. The total intensity increases above such electric currents because they produce northward horizontal magnetic field. This qualitatively explains the observed variations in the total intensity.

However, the problem is actually more complicated, because only the primary source current is taken into account in the above interpretation. Firstly, since the total electric currents (i.e. $\mathbf{I}=\sigma\left(\mathbf{E}+\mathbf{v} \times \mathbf{B}_{\mathbf{0}}\right)$, where $\mathbf{E}$ is the electric field) must be divergent free everywhere, the induced electric currents make a closed system flowing the other part of ocean and the conducting earth. Some portion of electric currents, i.e. a current loop in the vertical plane, produce a toroidal 


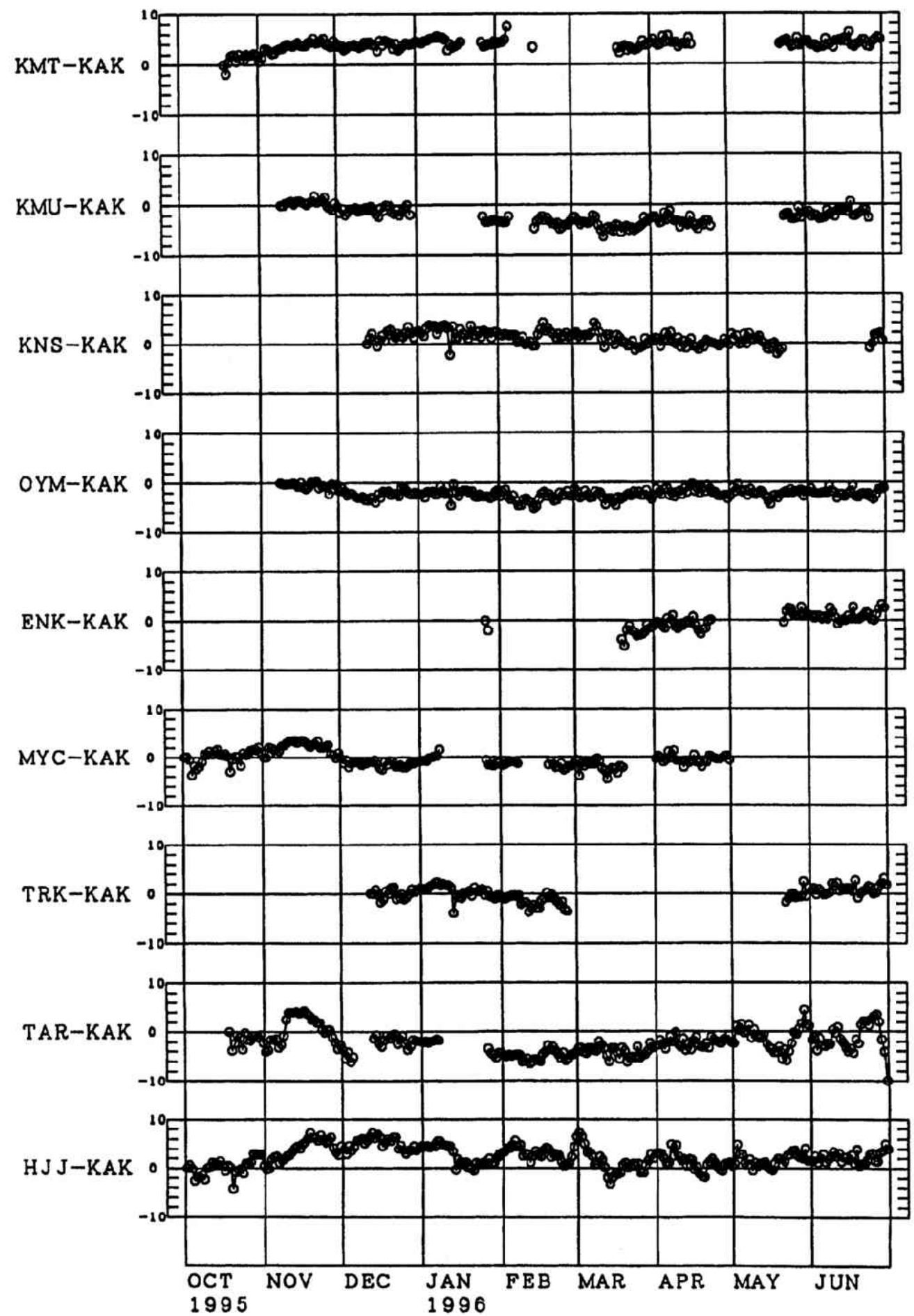

Fig. 5. The whole-day daily mean simple differences of the total force intensity between each station on Miyake-jima and KAK. The bottom graph shows the daily mean difference between HJJ and KAK using every minutes data. 
magnetic field, which is not observable above the ocean. Moreover, the time-varying electric currents induced by the dynamic ocean flow such as Kuroshio couple with the conducting earth electromagnetically.

Such a problem of motional induction by ocean flow was studied by Sanford (1971) and was formulated in a more generalized manner by Chave and Luther (1990). According to their studies, given a realistic model of the conductivity structure beneath the ocean floor, the horizontal electric field in the ocean is proportional to the vertically-integrated, conductivity (of sea water)-weighted horizontal water velocity smoothed over a certain horizontal scale. The qualitative explanation in the above is thus verified.

The second problem arises from the condition that we observe electromagnetic field on an island surrounded by the Kuroshio current flow. The turbulent water flow around the island would not produce significant EM field. However, the electromotive force by the broad Kuroshio flow $(\sim 100 \mathrm{~km})$ is intense enough to inject uniform electric currents into an inhomogeneous conducting sheet owing to the land-sea distribution. Then the island effect should occur as is the case for the ordinary electromagnetic induction by external field. The spatial discrepancy in the gradual total intensity variations on Miyake-jima island depicted in Fig. 5 is also most probably due to the island effect.

The third problem is the magnetic field generated by the overall pattern of the motionally induced electric currents. The meandering Kuroshio flow produces a large-scale non-uniform electric current system, which possibly accompanies with a substantial amount of vertical magnetic field as an integrated effect. Ueda et al. (1986) reported that the variation in the $Z$ component at HJJ had a good correlation with the meander of the Kuroshio current. This phenomenon can not be fully investigated by spatially limited observations on Miyake-jima and Hachijo-jima islands alone. We need well-distributed EM observations on other islands in Izu-Bonin Arc, on the ocean floor, and by submarine cables, together with current velocity and conductivity data.

The results shown in Figs. 3 and 5 indicates that the motionally induced field could be the most serious noise of natural origin for electromagnetic monitoring of Miyake-jima volcano. Elimination of this particular EM noise has never been attempted yet. However, the origin of the electric and magnetic fields is clear; we can estimate the intensity and direction of the uniform electric current flow around Miyake-jima island using the array observations of the magnetic field with the aid of a thin-sheet modeling technique (Sasai, 1968). This, in turn, gives information on the water flow. It is one of our main future subjects to find the way of properly eliminating the effect of the Kuroshio current flow. In order to apply the thin-sheet modeling, we need to know rather detailed subsurface resistivity structure of the island up to several hundreds $\mathrm{m}$ to a few $\mathrm{km}$ depth.

\section{Continuous Observations of the Self Potential}

Two continuous SP stations were installed on the volcano in October 1995 (Fig. 2). These stations simultaneously record the variations of the Self Potential on eight channels with a sampling rate of one value per minute. The accuracy is on the order of a ten of microvolts. Data are stored on a 4 Mbytes flash card. The power supply is provided by a $40 \mathrm{Ah} 12 \mathrm{~V}$ battery recharged by a $48 \mathrm{~W}$ solar panel. Non-polarized dry $\mathrm{Pb}-\mathrm{PbCl}_{2}$ electrodes (Petiau and Dupis, 1980) are buried between 50 and $80 \mathrm{~cm}$. At each station the configuration of the lines is equivalent: Two parallel lines are aligned with the local fissural axes, while the two other parallel lines are orthogonal. The topography of the volcano does not allow the use of very long dipoles. In the North station, called MYN, the longest lines are $195 \mathrm{~m}$ and $150 \mathrm{~m}$ along the North and East directions, respectively. In the South station, called MYS, the longest lines are $75 \mathrm{~m}$ and $100 \mathrm{~m}$ along the North and East directions, respectively.

At each station the mean daily SP values are computed along the North and East magnetic 


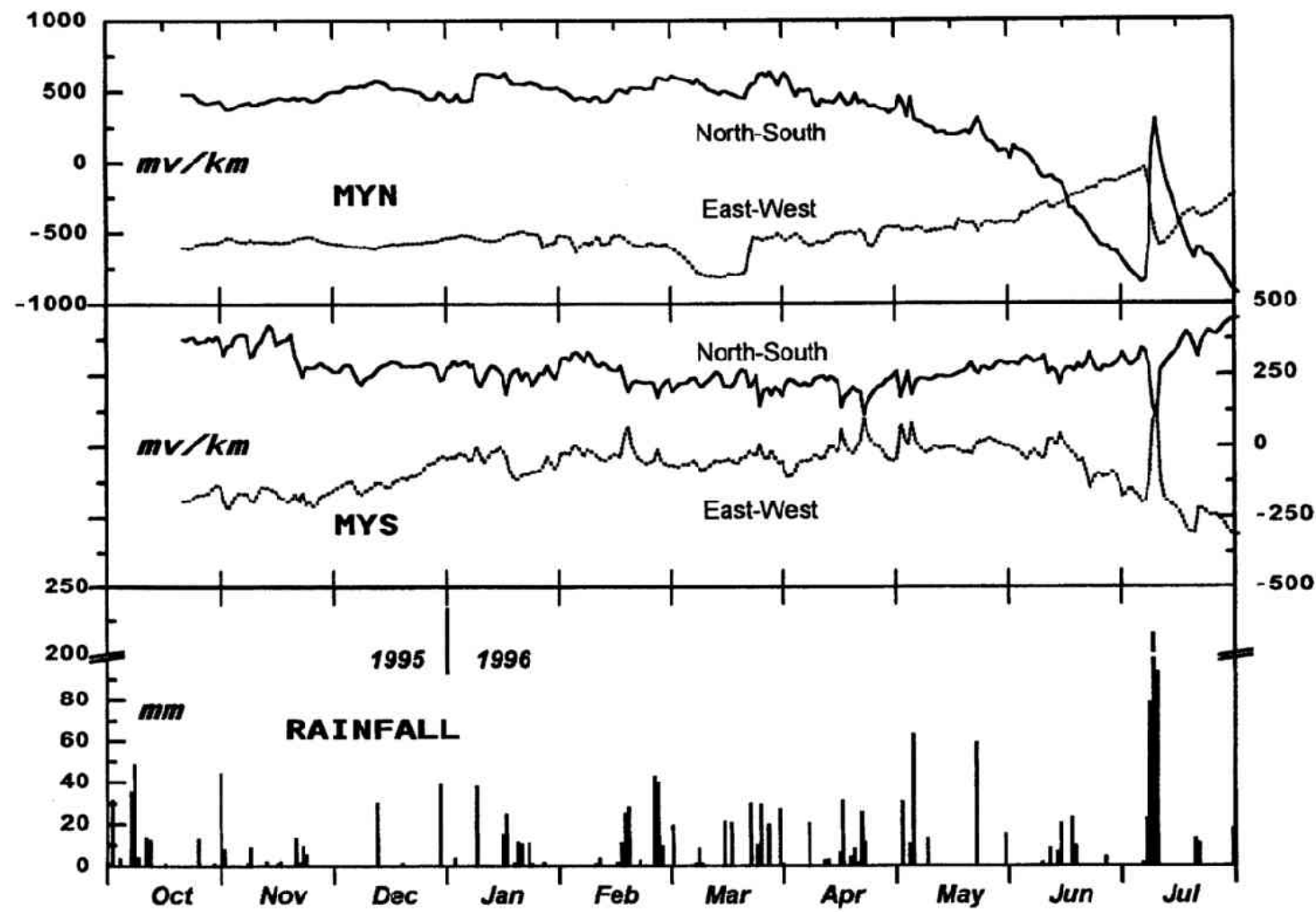

Fig. 6. The mean daily values of the N-S and E-W S.P. components at MYN and MYS stations. Daily rainfalls is presented.

directions (Fig. 6). Between October 1995 and July 1996 the variations can be split in several types.

Long term variations. Long term variations are present at both stations MYS and MYN. The time duration is several months or more. On the northern flank of the volcano the amplitude exceeds $1.5 \mathrm{~V} / \mathrm{km}$ on the North-South line (MYN station), while the amplitude is only one third on the southern flank (MYS station). Both stations present an extremum in the first fortnight of March 1996. A part of these variations could have a period of one year, as it is observed on several continuous SP stations implemented along the main fracture zone on Piton de la Fournaise volcano (Zlotnicki et al., 1996). This behavior can be attributed to seasonal rainfalls and temperature changes. It is noticeable that the extremum on the SP data coincides with the change in the rate of the mean daily rainfalls : Between October 1995 and March 1996 the rate is only $2.7 \mathrm{~mm} /$ day, while it abruptly reaches $6.0 \mathrm{~mm} /$ day beyond. The mechanism which generates variations correlated with the climatic changes can be described as follows: The combination of the seasonal rainfalls and temperature changes induce a phenomenon similar to the evapo-transpiration, in which the porosity - and therefore the permeability - of the uppermost layers of the volcano bedrocks are modified. The static pattern of the infiltrating meteoric water is disturbed, which produces cyclic electrokinetic variations.

Typical SP variations induced by rainfalls. In Fig. 6 daily rainfalls are plotted. An evident and well-known correlation between the rainfall and SP variations is observed. The amplitude of 

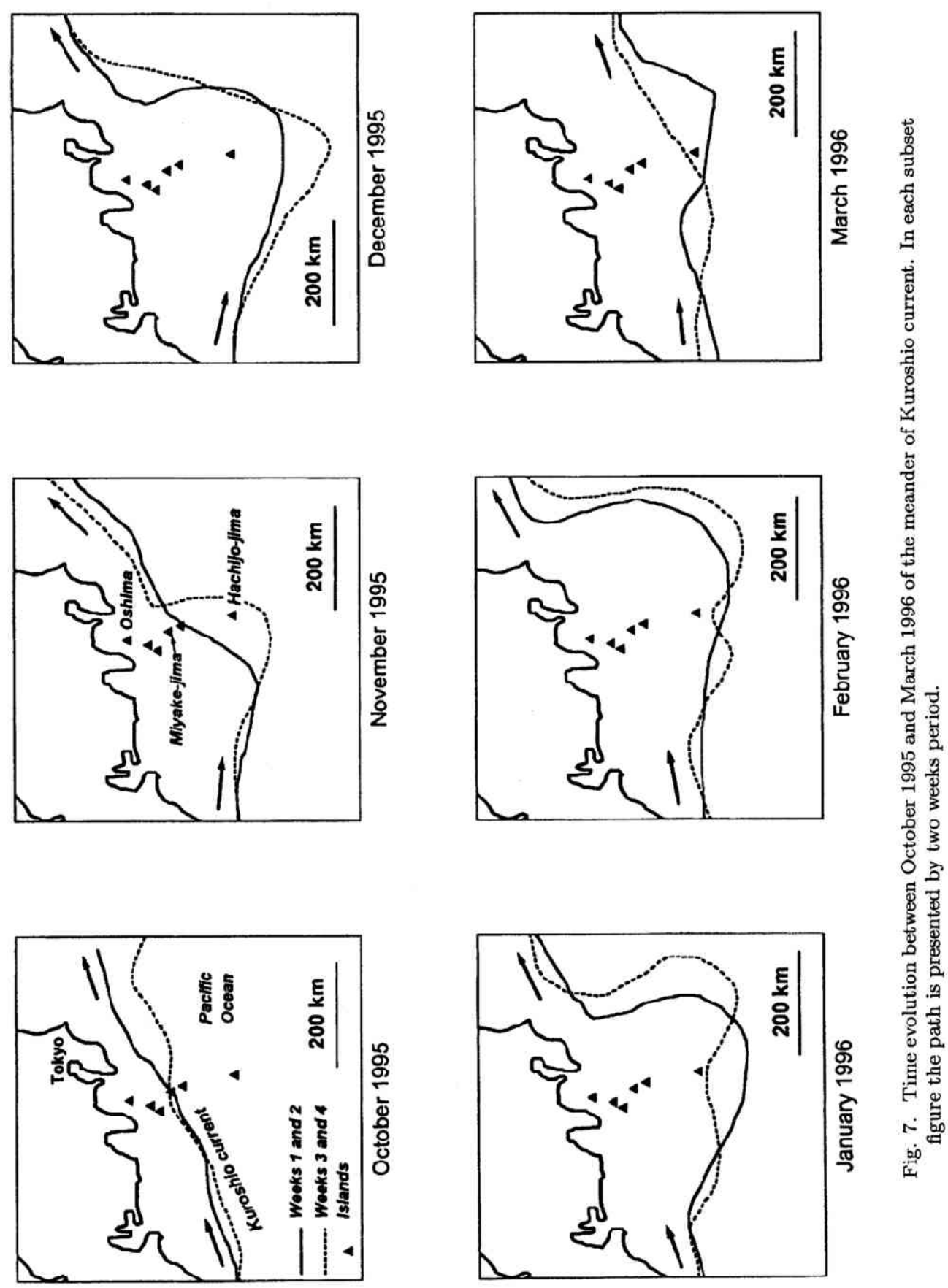
this induced effect is less than $150 \mathrm{mV} / \mathrm{km}$, except during the occurrence of a heavy rainfall in the rainy season of June 1996 where the amplitude on the North-South line at MYN has reached 1.2 $\mathrm{V} / \mathrm{km}$. It is clear that such induced peaks and their decay are an undesirable noise which could partly hide smoother and smaller SP variations generated by the activity of Miyake-jima volcano. Let us recall that the August 1992 fissure eruption on la Fournaise volcano has generated a 1.20 V SP anomaly which disappeared three months later (Zlotnicki et al., 1994b).

Motionally induced SP variations. As it has been described in the previous section, Miyakejima island is surrounded by the strong oceanic current Kuroshio. This $100 \mathrm{~km}$ wide, 2-4 knots speed, current changes in direction with time. Figure 7 presents the flow path between October 1995 and March 1996 by two weeks periods. Till October the direction of Kuroshio keeps a constant WSW to ENE direction. Early in November the current takes an West to East direction before to meander to the North along Hachijo-jima and Miyake-jima islands. This pattern slowly shifts to the East till March 1996 when the current recovers almost a WSW to ENE direction.

During the 6 month period from March to October Miyake-jima island does not experience large rainfall, and the SP variations are not largely affected by the typical SP variations induced by rainfalls. Figure 8 compares the SP variations with rainfall and with two characteristic magnetic variations on Miyake-jima and Hachijo-jima islands ((MYC-KAK) and (HJJ-KAK) daily mean differences). Magnetic variations recorded on Miyake-jima volcano have been described in the Section 4. Some of them are due to the modification of the path of the oceanic current Kuroshio. Under this hypothesis this current, which carries electric charges, should perturb the natural

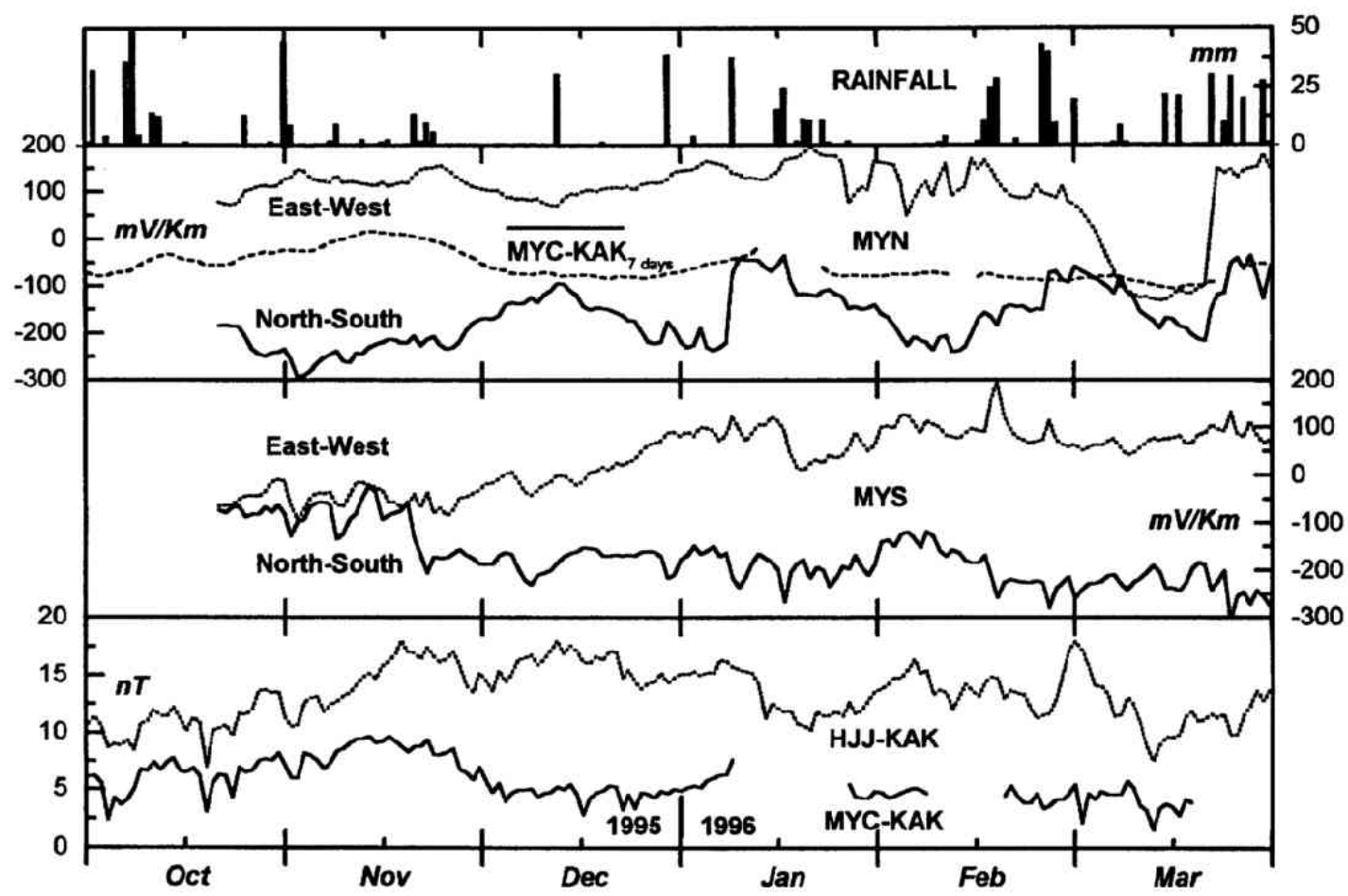

Fig. 8. (H.JJ-KAK) and (MYC-KAK) magnetic differences and mean daily SP variations at both MYN and MYS stations between October 1995 and March 1996. MYC-KAK days $_{\text {da }}$ is the running average over 7 days of the difference MYC-KAK. The daily pluviometry is at the top of the figure. 
electric field on the island.

First, there is no phase delay between the magnetic changes at MYC and HJJ and the modification of the Kuroshio meander : Both magnetic fields increase during the last week of October 1995. But the magnetic changes become inhomogeneous at the scale of the two islands due to the shift to the East of the South-North branch of the Kuroshio current in the second half part of November. Therefore it is understandable that HJJ magnetic station is affected during a longer period by the motionally induced current (a secondary effect is due to the location of HJJ station at the most southern tip of Hachijo-jima island).

Second, although the SP variations are more difficult to analyze owing to contamination by climatic disturbances and electrokinetic effects, it appears that - at least at MYN-an outstanding sinusoid shape is observed till January 1996 (Fig. 8). On the East-West SP line the variation follows the magnetic variation (MYC-KAK), whereas the variation on the North-South SP component is opposite. This pattern is less clear at MYS station where the SP variations seem opposite to those of MYN.

The correlation between the magnetic difference (MYC-KAK) and the SP components at MYN exhibits the motionally induced effect due to the Kuroshio current. A rough estimation of the effects of this current on the total force at MYC and on the SP components is $5 \mathrm{nT}$

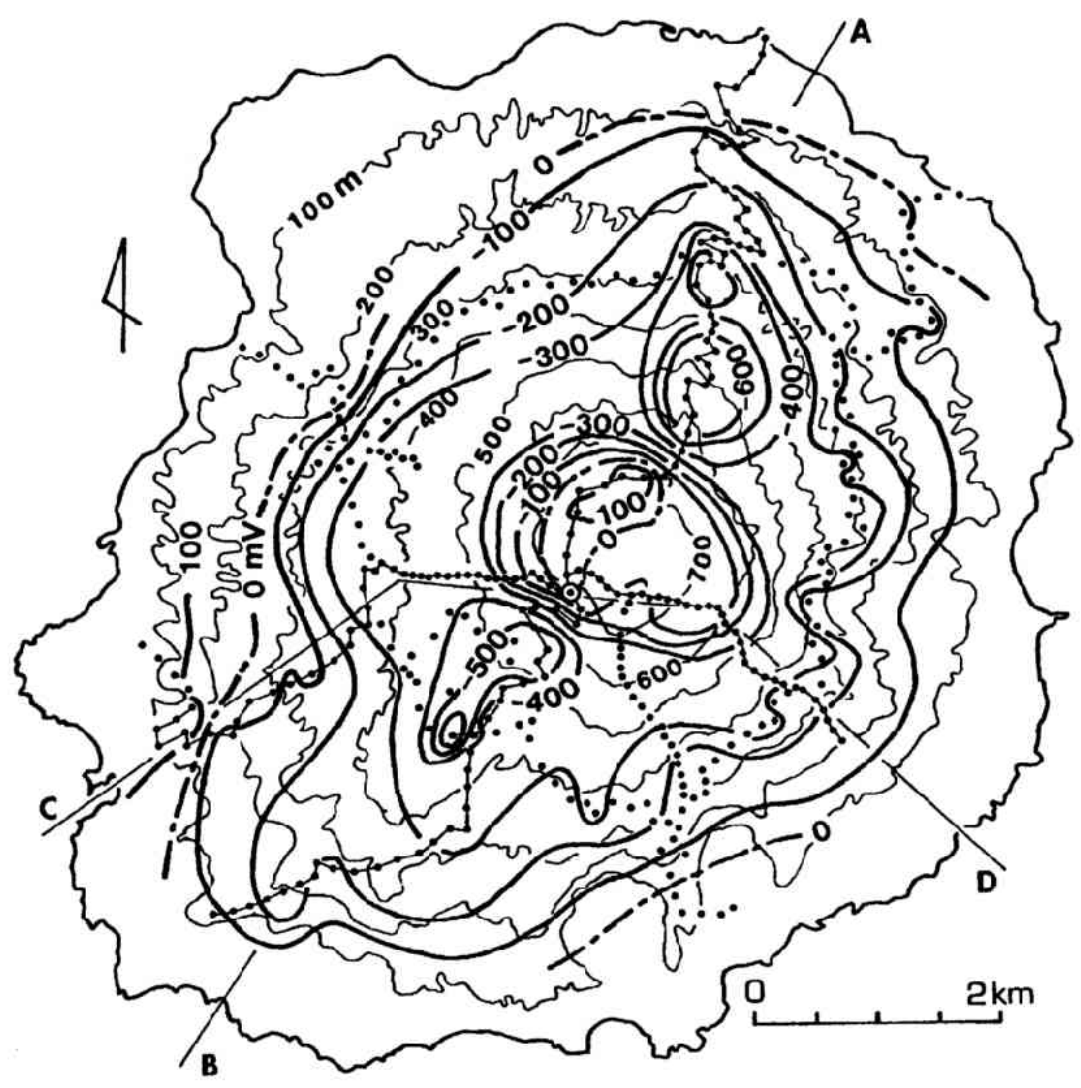

Fig. 9. Topographic map of Miyake-jima volcano (contour interval: $100 \mathrm{~m}$ ), survey stations (solid circles) and contour map of the SP distribution measured in 1995 and 1996 (contour interval: $100 \mathrm{mV}$ ). The double circle denotes the reference station. 
and $100 \mathrm{mV} / \mathrm{km}$, respectively. The motionally induced SP variations seem opposite here and there of Miyake-jima volcano summit, like the magnetic variations are (Fig. 4). The island effect could explain these observations and three-component magnetic recordings should be attempted to interpret them.

In spite of the short time records (only six months) it appears that the magnetic variations observed on Miyake-jima volcano correspond to some trends recorded at least at the northern SP MYN station. Together with electrokinetic effects due to the seasonal rainfalls and the hydrothermal system created by the interaction between the meteoric waters drained within the volcano and their interactions with a deep thermal source, some of the SP variations can be explained by an induced ocean current effect. The simultaneous changes of the features of both magnetic and electric variations, which occur when the path of the Kuroshio oceanic current shifts, supports this hypothesis.

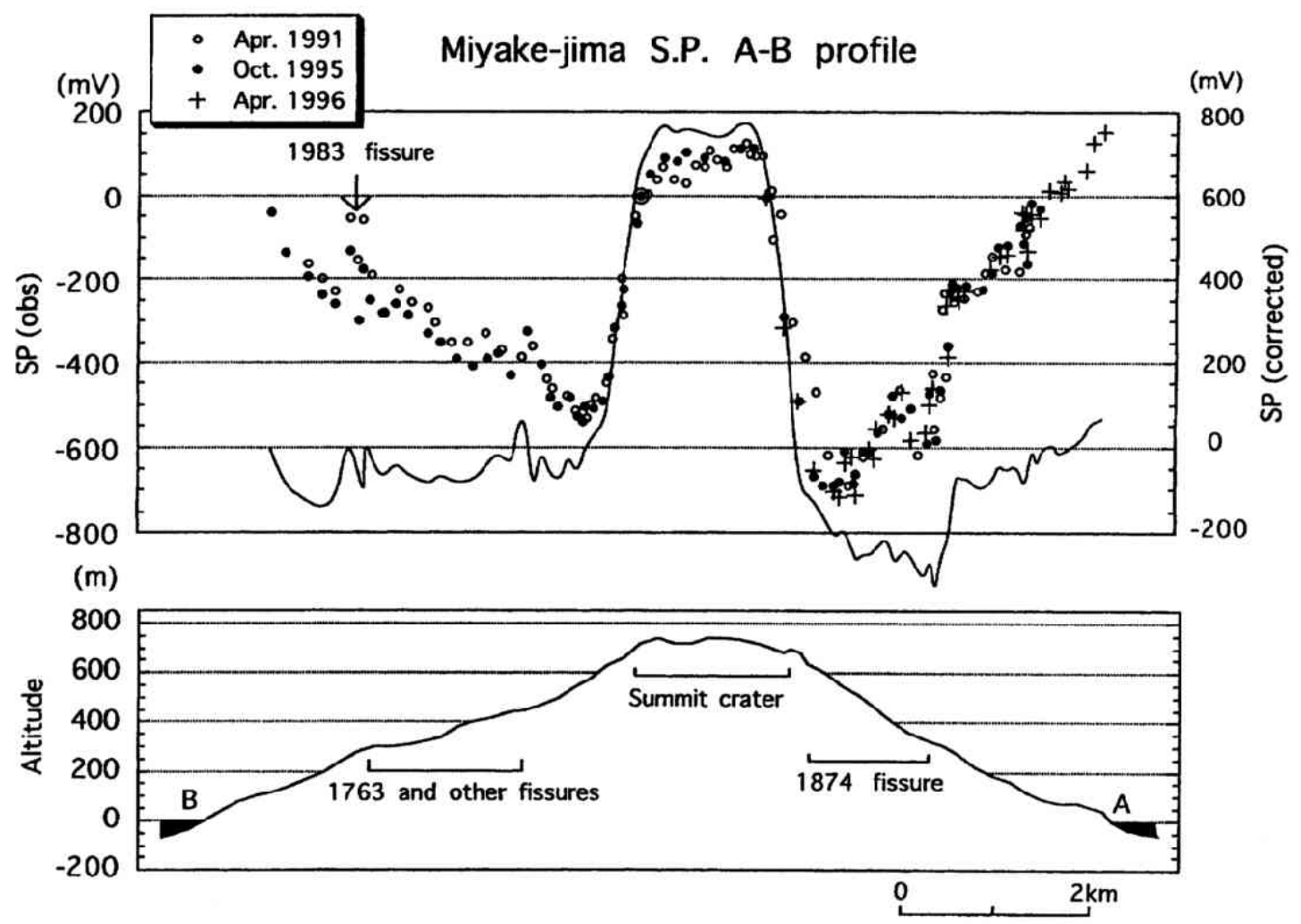

(a)

Fig. 10. Observed SP values measured in 1991 (hollow circles), 1995 (solid circles) and 1996 (crosses). The values are represented as the relative ones to the reference station (double circle in Fig. 9). Observation points linked with thin lines (Fig. 9) are projected onto lines (a) A-B and (b) C-D in Fig. 9. Solid line shows SP values corrected for the mean terrain effect $(-1.07 \mathrm{mV} / \mathrm{m})$. Topographic profiles are also shown. 


\section{Self-Potential Mapping on Miyake-jima Volcano}

We made a reconnaissance survey of the SP field on Miyake-jima volcano in April, 1991 along a traverse line crossing the Miyake-jima island (observation points, which are linked with a thin line, along A-B in Fig. 9). The equipment for measurements was composed of a pair of non polarizing copper-copper sulfite electrodes and a high impedance voltmeter. The observed values are plotted along the traverse line as shown by hollow circles in Fig. 10(a). The values are represented as the relative ones to the tentative reference point (the double circle in Figs. 9 and 10). The terrain related SP fields are clearly seen on the foot of Miyake-jima: SP decreases as the ground surface elevation increases. Exclusive of the terrain effect, a relatively positive anomaly is noticeably found in the central part of the volcano.

This initial finding encouraged additional studies and we made systematic SP surveys in October, 1995 and supplementally in April, 1996 to confirm a detailed picture of the SP fields over a major part of Miyake-jima island. Figure 10 (a) shows the SP values measured repeatedly in 1991, 1995 (solid circles) and 1996 (crosses) along the traverse line A-B. We find that data reproducibility is fairly good. This implies the reliability of our measurements, together with the stable existence of the SP anomalies on this volcano.

Measurements were made twice at several points during each survey to correct closure errors. The corrected data are compiled as shown in Fig. 9 with a contour interval of $100 \mathrm{mV}$. The positive

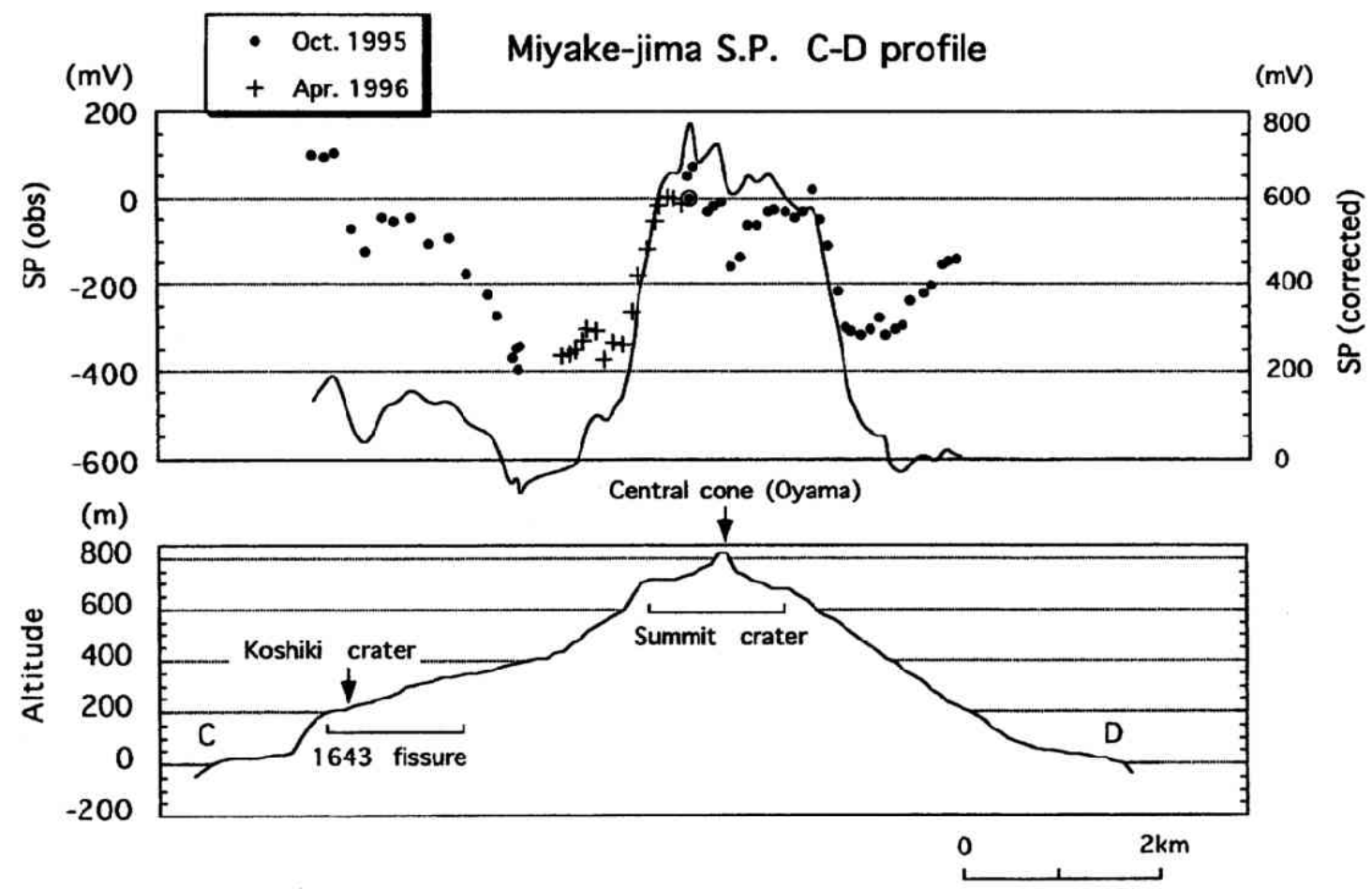

(b)

Fig. 10. (continued). 
anomaly over the summit area is the important feature of the present survey as mentioned above. Relatively low SP anomalies (contours below $-400 \mathrm{mV}$ ) on the north and the south mountainsides are apparent.

The terrain effect is easily seen in the correspondence between SP and altitude below altitudes of about 450 meters, where it is not complicated by the presently active volcanism (Fig. 11). A linear least-squares regression analysis on the data yields the following fit to these SP data (in this analysis, we exclude the data observed on the north mountainside, which are considerably lower than others):

$$
S P=108.7-1.07 H
$$

where $S P$ is the electric potential value in $\mathrm{mV}$ and $H$ is the sampling point elevation in meters above sea level. A coefficient of correlation is -0.83 . Thus, we can evaluate the anomalies related with volcanic activity and other annexed phenomena by removing the terrain effect from the observed anomalies.

The SP anomalies corrected of a mean terrain effect are shown in Figs. 10(a) and (b) for traverse lines A-B and C-D (Fig. 9) with solid curves. The main positive anomaly over the summit area amounts to more than $700 \mathrm{mV}$ while the negative anomalies on the north and the south mountainsides are about $-250 \mathrm{mV}$ and $-100 \mathrm{mV}$, respectively (the A-B line). The negative anomaly on the north mountainside corresponds well with the distribution of many craters connected with a fissure zone formed in 1874, while that on the south mountainside is correlated with the fissures formed in 1763 and older ages (Isshiki, 1960; Nakamura, 1984). Watanabe (unpublished) found a positive anomaly of about $300 \mathrm{mV}$ on the 1983 fissure two weeks after the eruption. We can also see a positive anomaly ( $100 \mathrm{mV}$ or so) on the 1983 fissure, although the spatial wavelength is very short. Therefore, this small-scale anomaly has survived during this decade. Negative anomalies are not observed on the mountainsides of the traverse line C-D. In addition to the main positive anomaly, an appreciable positive anomaly (150 $\mathrm{mV}$

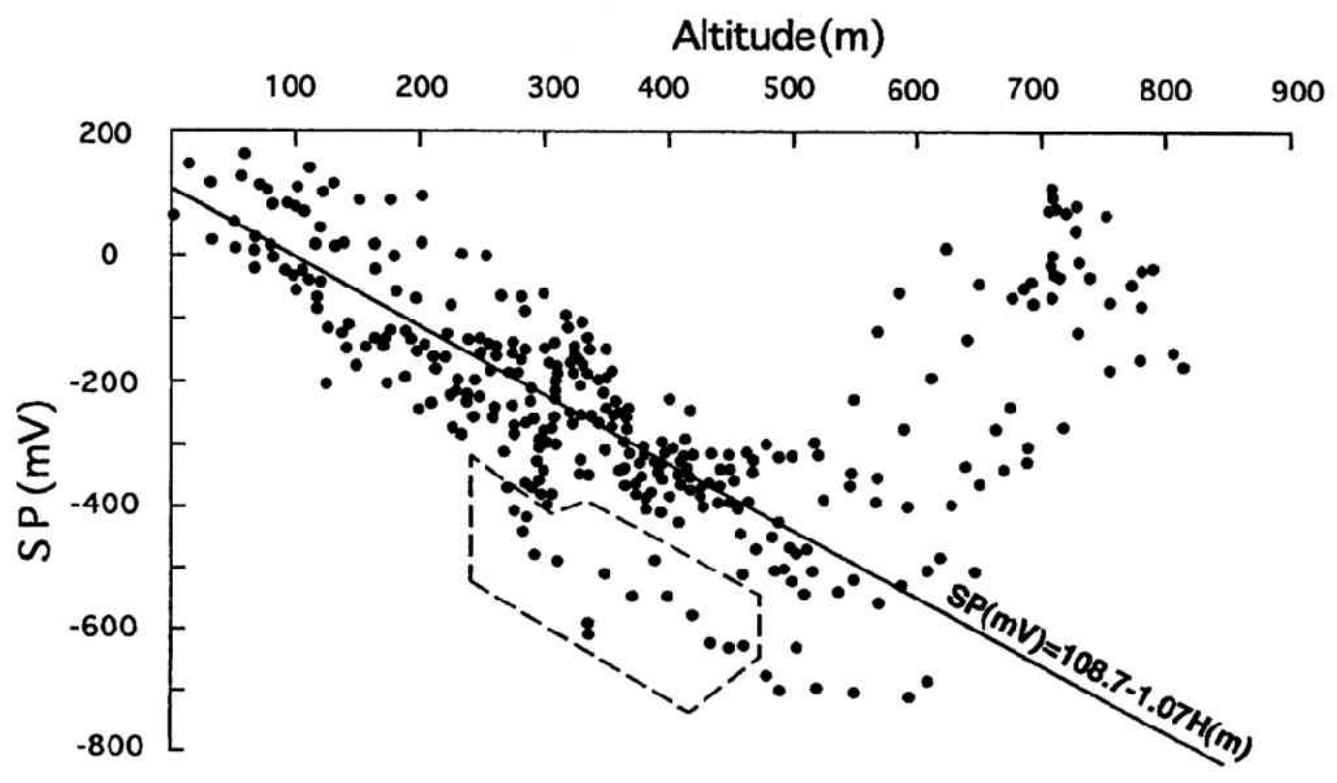

Fig. 11. SP values are plotted against ground elevation. A regression line is also shown (the data which are surrounded by dashed polygon are excluded in this analysis). 
or so) is situated around an explosion crater, Koshiki, of which recent activity is inferred to be effusion of lava flows in 1643 (see Fig. 10(b)).

The origin of SP anomaries on volcanic regions is not fully understood. However, there are several possible explanations: electrochemical coupling, oxidation-reduction reaction, thermoelectric coupling and electrokinetic coupling effects. Among these mechanisms, the former three may be ruled out as the source mechanism of the positive anomaly amounting to about 700 $\mathrm{mV}$ over the summit area of Miyake-jima volcano. The electrochemical potentials do not exceed about $20 \mathrm{mV}$ in the ordinary geothermal area except in the special cases such as an alunite field (Nourbehecht, 1963; Corwin and Hoover, 1979). The oxidation-reduction effect caused by reactions between the volcanic gases and the ground water generates negative potentials and hence, the effect cannot be a source mechanism for the positive anomaly. The thermoelectric potential gives only about $30 \mathrm{mV}$ for a realistic value of the thermoelectric coupling coefficient even if we assume large temperature difference of $1000^{\circ} \mathrm{C}$ (Nourbehecht, 1963; Corwin and Hoover, 1979).

Ishido (1981) presented a theoretical model that electrokinetic potentials caused by upward movement of heated ground water are the principal cause of the large positive anomalies while those associated with descending meteoric water are responsible for the negative anomalies. Taking account of his model, we would conclude that substantial amount of the precipitation (more than 3,000 mm/year) over Miyake-jima island probably recharges highly permeable fissures and craters formed in 1874 and 1763 to generate the observed negative SP anomalies. Hot volcanic gas from relatively deep-seated magma intrudes into the recharged water to drive the intensive upward flow of the heated water and thereby the large positive SP anomaly is generated on the summit area. Magnetotelluric soundings detected a low resistivity area about $300 \mathrm{~m}$ below the summit crater floor (Utada et al., 1984). The upward flow forms this hydrothermal aquifer, which maintains the fumarolic fields, alias 'Sauna' and others in the summit crater.

However, the signs of small-scale SP anomalies are not always consistent with the above interpretation: Why do the positive anomalies appear on the explosion crater, Koshiki, and the 1983 fissure, which is contrary to the negative anomalies on other fissures and craters formed in 1874 and 1763 ? We present an idea which may explain the discrepancy as follows:

Intensive upward flow of hot groundwater is probably predominant in a newly formed fissure such as the 1983 one; hence, the positive anomaly appears on the earth's surface. As the thermal activity declines, recharge of heavy precipitation may overcome the upward flow in the permeable fissure; thereby the downward flow generates the negative anomaly, which are the cases for the 1874 and 1763 fissures. Further progress of time gives rise to choking of the near surface fissure and/or crater due to argillization accompanied by hydrothermal alteration (Zlotnicki et al., 1994a), and fine ash deposition, to prevent the invasion of the precipitation to depth. Eventually, hot water may again come up through the existing fissure at depth to generate a weak positive anomaly as is the case for Koshiki anomaly. To confirm this hypothesis, however, further SP and hydrological data are required.

\section{Further Subjects}

As has been stated in the introduction, our monitoring system on Miyake-jima volcano aims to capture the silently uprising magma by the combined electromagnetic observations of magnetic field, resistivity and self potential. In that sense, our system is still insufficient and incomplete; in particular, the lack of resistivity measurement is a crucial problem. Moreover, as compared with the case of Izu-Oshima volcano, we are required to improve the detection capability of resistivity changes at a rather deeper portion within the volcano. Most probably in the next eruption, the magma will not come up through the shallower vent.

We plan the following observations in the near future:

(1) Continuous observation of resistivity by magneto-telluric method on the summit caldera. 
(2) Continuous measurement of SP around the fumarole activity area in the summit caldera.

(3) Long-distance SP measurement over the island using the telephone cables and monitoring resistivity changes by means of network MT technique (Uyeshima et al., 1997).

(4) Continuous measurement of resistivity at a depth of a few $\mathrm{km}$ by the controlled source TDEM (Time Domain ElectroMagnetic) method.

We have already installed an equipment for (1) in the summer of 1996 (OYC in Fig. 2). As has been discussed in Sections 3 and 4, we need detailed knowledge of rather shallow subsurface resistivity structure beneath Miyake-jima island. This is because it gives us definite information on the location of acquifers, i.e. the sources of electromagnetic signals related to volcanic activity, and because it enables us to quantitatively estimate motionally-induced electric currents due to the Kuroshio ocean flow with the aid of thin-sheet modeling. Hence, we plan to carry out resistivity survey by audio-frequency MT method in the near future. Detailed analyses of electromagnetic data on Miyake-jima volcano will be reported elsewhere by respective authors.

We are greatly indebted to Hideyuki Satoh, Mitsuru Utsugi (Hokkaido Univ.) and Kazuhiro Amita (Kochi Univ.) for their great efforts in the field work. J. L. Le Mouel, Director of the Institut de Physique du Globe de Paris, has always supported our Japan-French scientific cooperation by promoting it and by efficient discussions. We are also thankful to Drs. Hidefumi Tanaka (Kochi Univ.) and Malcolm J. S. Johnston (USGS) for their useful discussion and kind help during the surveys. Malcolm Johnston and an anonymous reviewer gave us very useful suggestions to improve the manuscript. Those in Miyake Village Office and Miyake Local Office of the Tokyo Metropolitan Government have given us enough facilities for our observations. This study was supported in part by the Grant-in-Aid for Scientific Research (C) No. 07640549 from the Ministry of Education, Science, Sports and Culture, Japan and by the French Embassy in Tokyo, the Ministry of Foreign Affairs, France. P. M. and J. Z. were supported by CNRS-JSPS exchange program in 1995 and 1996, respectively.

Appendix: Magma Plumbing System of Miyake-jima Volcano in the Case of the 1983 Eruption

The most recent eruption of Miyake-jima volcano, i.e. on October 3, 1983, was better investigated than the eruptions in 1940 and 1962 . However, in 1983 we still had very few continuous observations, only one seismometer but no electromagnetic data. Fortunately, we had conducted various kinds of electromagnetic surveys in 1980 and these results were compared with the observations just after the eruption. The data sources and discussions on the eruption mechanisms are summarized in a few special issues.

Based mainly on electromagnetic observations (Kawamura et al., 1982; Yukutake et al., 1982; Nakagawa et al., 1984; Utada et al., 1984), Sasai, Utada and Nakagawa (1984) inferred the eruption mechanism of this volcano in 1983. Figure 12 shows a schematic representation of what may have occurred beneath the volcanic island before, during and after the eruption. Some important features are as follows:

1) Magma was injected to a depth of $3 \mathrm{~km}$ just below the summit $(2.6 \mathrm{~km}$ below the sea level: Mark (A) in Fig. 12). This was inferred from total intensity changes (Nakagawa et al., 1984). Continued magma intrusion occurred upward toward the southwest, which resulted in the flank fissure eruption (B) and phreatomagmatic explosion near the coast (B').

2) Possibly magma stayed at (A) for a short period of time. This is because the demagnetized area was estimated to be very small.

3) The vent from (A) to the summit crater appeared to be blocked. Since no drastic thermal demagnetization occurred at shallow depth in the summit. Enlargement of a hydrothermal acquifer (C) below the crater was detected by repeat MT surveys. 


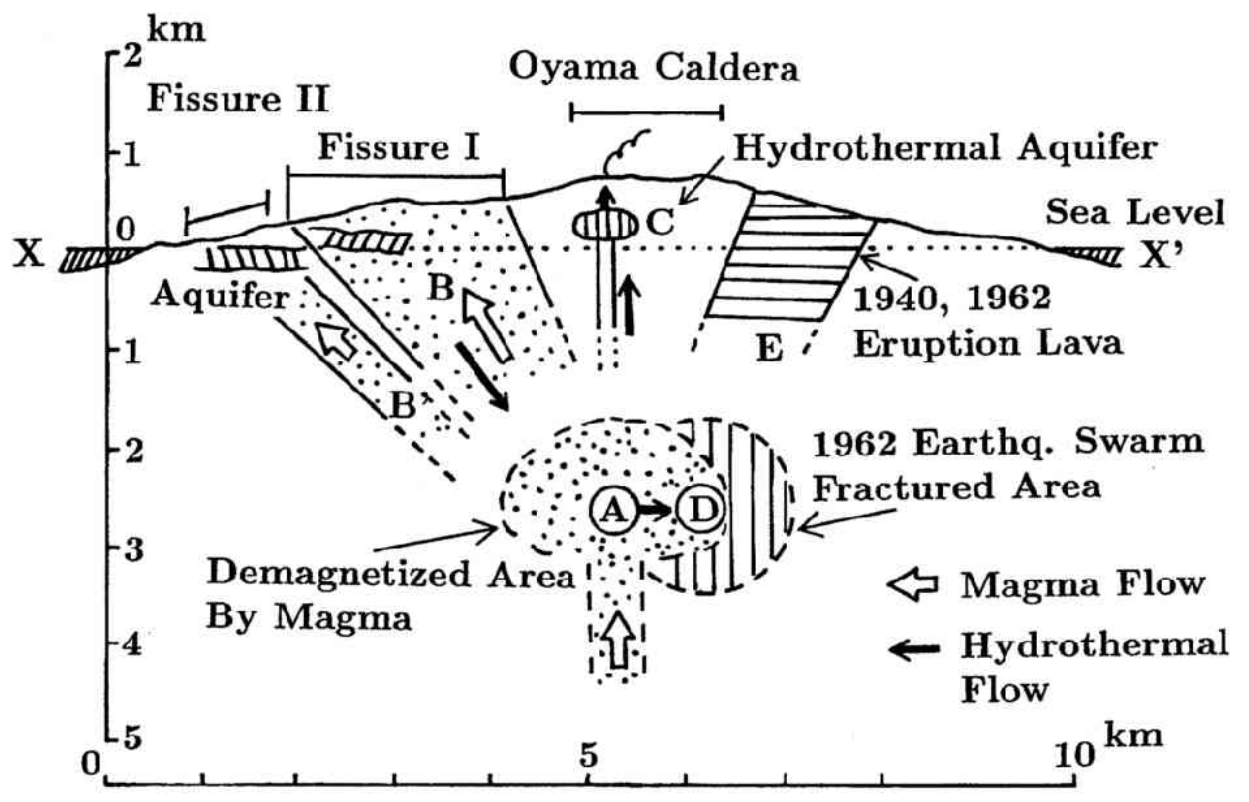

Fig. 12. A schematic view of the 1983 eruption of Miyake-jima volcano (after Sasai et al., 1984). A vertical cross section across the NE-SW line through the central cone Oyama is shown.

4) However, the vent appeared to be more permeable to hydrothermal materials in 1983 than in 1962. The activation of the summit fumarole started one year after the 1962 eruption, in contrast to one month after in 1983.

5) During the period from November to December, 1983, a thermally demagnetized area (D) was formed $3 \mathrm{~km}$ below the northern rim of the summit caldera. This was ascribed to diffusion of hot hydrothermal materials. The area (D) coincides with the earthquake swarm area after the 1962 eruption and was supposed to be porous enough for fluid penetration.

6) Phreatomagmatic explosions took place near the coastline owing to contact of magma with a sea-water bearing acquifer (H-L1). No such explosion occurred at the old caldera floor on the western flank where an aquifer with water of meteoric origin (HL-2) exists.

7) The fissure zones produced by eruptions in the southwest (1983) as well as those in the north (1874) and northeast $(1940,1962)$ are highly resistive. This is most probably due to their very porous state with no connected water rather than due to massive lava. A possibility is suggested that a plenty of rainwater penetrated through (B) and (B') into (A), was heated up by the remnant heat, and was supplied to (C) and (D). This is also an effective cooling system of this volcano; otherwise, heat should accumulate inside to cause a big scale thermal demagnetization. No such a magnetic change was observed.

Yamamoto et al. (1993) compiled the results of repeat magnetic surveys since 1980. They suggested remagnetization occurred somewhere above (A) toward (C) since late 1980's. This implies that thermal demagnetization had taken place in the upper portion of the vent, most likely before the 1983 eruption. If demagnetization in this part is detected again, it could be a useful precursor to the coming eruption. We may require a more dense network of magnetometers to discriminate the changing geometry of the demagnetized area.

Kagiyama et al. (1988) investigated the causes of precursory temperature changes before eruptions. They classified Miyake-jima volcano as a typical example of active volcanoes presenting 
no thermal precursor because the impermeable vent of Miyake-jima restricts weak fluid injection. However, a summit eruption did occur on Miyake-jima in 1940. Taking into account the fact described in 4) and Yamamoto et al.'s (1993) result, we cannot discard a possibility that the permeability of the vent is increasing.

The recent field work of SP measurements (see Section 5) presented new evidence to support the suggestion in 7) in the above. They found two big negative anomalies in the north and southwestern fissure zones as well as high SP values around the summit caldera. The negative SP anomalies are produced by the downflow of groundwater, while the positive one by upwelling of heated water towards the crater. In other words, the fissure zones make "windows" open to the core zone beneath the crater, which controls the eruption process of Miyake-jima volcano.

\section{REFERENCES}

Aramaki, S., Y. Hayakawa, T. Fujii, K. Nakamura, and T. Fukuoka, The October 1983 eruption of Miyake-jima volcano, J. Volcanol. Geortherm. Res., 29, 203-229, 1986.

Ballestracci, R. and Y. Nishida, Fracturing associated with 1977-1978 eruption of Usu volcano, North Japan, as revealed by geophysical measurements, J. Volcanol. Geotherm. Res., 34, 107-121, 1987.

Chave, A. D. and D. S. Luther, Low-frequency, Motionally induced electromagnetic fields in the ocean. 1. Theory, J. Geophys. Res., 95, C5, 7185-7200, 1990.

Corwin, R. F. and D. B. Hoover, The self potential method in geothermal exploration, Geophysics, 44, 226-245, 1979.

Delorme, H., P. Bachelery, P. A. Blum, J. L. Cheminee, J. F. Delarue, J. C. Delmond, A. Hirn, J. C. Lepine, P. M. Vincent, and J. Zlotnicki, March 1986 eruptive episodes at Piton de la Fournaise volcano (Reunion Island), J. Volcanol. Geotherm. Res., 36, 199-208, 1989.

Electromagnetic Research Group of Izu-Oshima Volcano, Electromagnetic observations of Izu-Oshima volcano during its eruptions in 1986, Proc. 'Kagoshima International Conference on Volcanoes 1988', 191-194, 1988.

Hagiwara, T., Changes in earth potential after the eruption, Bull. Earthq. Res. Inst., 19, 367-372, 1941.

Hashimoto, T. and Y. Tanaka, A large self-potential anomaly on Unzen volcano, Shimabara Peninsula, Kyushu Island, Japan, Geophys. Res. Lett., 22, 191-194, 1995.

Honkura, Y., Geomagnetic variation anomaly on Miyake-jima Island, J. Geomag. Geoelectr., 23, 307-333, 1971.

Honkura, Y., Island effect and electrical conductivity structure beneath Miyake-jima Island, J. Geomag. Geoelectr., 25, 167-179, 1973.

Ishido, T., Streaming potential associated with hydrothermal convection in the crust: a possible mechanism of self-potential anomalies in geothermal areas, J. Geotherm. Res. Soc. Japan, 3, 87-100, 1981 (in Japanese with English abstract).

Ishido, T. and H. Mizutani, Experimental and theoretical basis of electrokinetic phenomena in rock-water systems and its applications to geophysics, J. Geophys. Res., 86, 1763-1775, 1981.

Isshiki, N., Explanetory Text of the Geological Map of Japan (scale 1:50,000): Miyake-jima., pp. 1-85, Geol. Surv. Jpn., 1960 (in Japanese with English abstract).

Isshiki, N., Mode of eruption of Miyake-jima volcano in historic times, Bull. Volcanol., 27, 29-48, 1964.

Kagiyama, T., H. Utada, and Y. Sasai, Controlling factor of occurrence of thermal precursor of volcanic eruptions, Proc. 'Kagoshima International Conference on Volcanoes 1988', 187-190, 1988.

Kagiyama, T., H. Utada, and T. Yamamoto, Magma rising process of Unzen volcano estimated from the electrical resistivity structure, Proc. the '95 International Workshop on Volcanoes Commemorating the 50th Anniversary of Mt. Showa-Shinzan, 69-72, 1995.

Kato, Y., The changes in the earth's magnetic field accompanying the volcanic eruption of Miyake-zima, Proc. Imp. Acad. Japan, 16, 467-472, 1940.

Kato, Y. and I. Muroi, The changes of the earth's magnetic field accompanying the volcanic eruption of Miyakeshima, Sci. Rep. Tohoku Univ., Ser. 5, 15, 33-44, 1963.

Kawamura, M., K. Ohchi, T. Koike, O. A. Veliz-Castillo, T. Yukutake, T. Yoshino, and H. Utada, Geomagnetic observations on Miyake-jima volcano, Report of the First Joint Geophysical Observations of Miyake-jima Volcano (1980), 31-42, 1982 (in Japanese).

Matsushima, N., M. Michiwaki, N. Okazaki, R. Ichikawa, A. Takagi, Y. Nishida, and H. Mori, Self-potential studies in volcanic areas (2)-Usu, Hokkaido Komaga-take and Me-akan-, J. Fac. Sci., Hokkaido Univ., Ser. 7, 8, 465-477, 1990.

Michel, S. and J. Zlotnicki, Is la Fournaise volcano eruptive activity controlled by the N120 ${ }^{\circ}$ lithospheric structural anisotropy located beneath Reunion Island?, C. R. Acad. Sci. Paris, 321, Ser. II, 643-650, 1995 (in French with extended English abstract).

Minakami, T., A magnetic dip survey of Miyake-jima Island, Bull. Earthq. Res. Inst., 19, 356-362, 1941.

Minakami, T., The 1962 eruption of Miyake-sima, one of the Seven Izu Island, Japan, Bull. Volcanol., 27, 225-235, 
1964.

Nagata, T., Anomalous change in geomagnetism accompanying volcanic activity, Bull. Earthq. Res. Inst., 19, 335-355, 1941.

Nagata, T., The natural remanent magnetism of volcanic rocks and its relation to geomagnetic phenomena, Bull. Earthq. Res. Inst., 21, 1-196, 1943.

Nakagawa, I., Y. Sasai, H. Utada, Y. Ishikawa, S. Koyama, K. Ohchi, and T. Tokumoto, Changes in total intensity of the geomagnetic field associated with the 1983 eruption of Miyake-jima volcano, Bull. Volcanol. Soc. Japan, Ser. 2, 29, S101-S112, 1984 (in Japanese with English abstract).

Nakamura, K., Distribution of flank craters of Miyake-jima volcano and the nature of ambient crustal stress field, Bull. Volcanol. Soc. Japan, 29, S16-S23, 1984 (in Japanese with English abstract).

Nishida, Y. and H. Tomiya, Self-potential studies in volcanic areas (1)-Usu volcano-, J. Fac. Sci., Hokkaido Univ., Ser. 7, 8, 173-190, 1987.

Nishida, Y., H. Satoh, M. Utsugi, H. Murakami, K. Amita, J. Zlotnicki, P. Yvetot, P. Morat, Y. Sasai, and Y. Ishikawa, A preliminary report on the distribution of the self-potential field in Miyake-jima volcano, Proc. Conductivity Anomaly Symposium (1996), 247-253, 1996 (in Japanese).

Nourbehecht, B., Irreversible thermodynamic effects in inhomogeneous media and their applications in certain geologic problems, Ph.D. Thesis, Mass. Inst. Technol., Cambridge, 1963.

Petiau, G. and A. Dupis, Noise, temperature coefficient, and long term stability of electrodes for telluric observations, Geophys. Prospect., 28, 792-804, 1980.

Sanford, T. B., Motionally-induced electric and magnetic fields in the sea, J. Geophys. Res., 76, 3476-3492, 1971.

Sasai, Y., Spatial dependence of short-period geomagnetic fluctuations on Oshima island (1), Bull. Earthq. Res. Inst., Univ. Tokyo, 45, 137-157, 1967.

Sasai, Y., Spatial dependence of short-period geomagnetic fluctuations on Oshima island (2), Bull. Earthq. Res. Inst., Univ. Tokyo, 46, 907-926, 1968.

Sasai, Y. and Y. Ishikawa, Changes in the geomagnetic total force intensity associated with the anomalous crustal activity in the eastern part of the Izu Peninsula (5) - 1982-1984 Off-Kawanazaki swarm earthquakes and crustal uplift-, Bull. Earthq. Res. Inst., Univ. Tokyo, 60, 147-177, 1985 (in Japanese with English abstract).

Sasai, Y. and Y. Ishikawa, Tectonomagnetic signals related to the seismovolcanic activity in the Izu Peninsula, $J$. Phys. Earth, 39, 299-319, 1991.

Sasai, Y., H. Utada, and I. Nakagawa, The 1983 eruption of Miyake-jima volcano as viewed from electromagnetic observations, Earth Monthly, 6, 716-724, 1984 (in Japanese).

Sasai, Y., T. Shimomura, Y. Hamano, H. Utada, T. Yoshino, S. Koyama, Y. Ishikawa, I. Nakagawa, Y. Yokoyama, M. Ohno, H. Watanabe, T. Yukutake, Y. Tanaka, T. Yamamoto, K. Nakaya, S. Tsunomura, F. Muromatsu, and R. Murakami, Volcanomagnetic effect observed during the 1986 eruption of Izu-Oshima volcano, J. Geomag. Geoelectr., 42, 291-317, 1990.

Sasai, Y., Y. Ishikawa, Y. Nishida, H. Satoh, M. Utsugi, H. Murakami, K. Amita, H. Tanaka, J. Zlotnicki, P. Yvetot, and P. Morat, Joint cooperative electromagnetic observations of Miyake-jima volcano in 1995, Proc. Conductivity Anomaly Symposium (1996), 237-247, 1996 (in Japanese).

Takahasi, R. and K. Hirano, Changes in the vertical intensity of geomagnetism that accompanied the eruption of Miyake-jima in 1940, Bull. Earthq. Res. Inst., 19, 82-103, 1941a.

Takahasi, R. and K. Hirano, Changes in the vertical intensity of geomagnetism that accompanied the eruption, Bull. Earthq. Res. Inst., 19, 373-380, 1941 b.

Tanaka, Y., Eruption mechanism as inferred from geomagnetic changes with special attention to the 1989-1990 activity of Aso volcano, J. Volcanol. Geotherm. Res., 56, 319-338, 1993.

Tanaka, Y., Volcanomagnetic effects on the Unzen volcano (1990-1992), J. Geomag. Geoelectr., 47, 325-336, 1995.

Tsuya, H., Geological observations of the Miyake-sima eruption of 1940 (I), Bull. Earthq. Res. Inst., 19, 263-324, 1941.

Ueda, Y., N. Higashi, S. Oshima, and S. Okubo, Geomagnetic variations induced by Kuroshio current observed at Hatizyo Sima Island, J. Geod. Soc. Japan, 32, 83-84, 1986 (in Japanese with English abstract).

Utada, H., Interpretation of the apparent resistivity change prior to the 1986 eruption of Izu-Oshima volcano (I), Programme and Abstracts of Volcanol. Soc. Japan, Fall meeting of 1991, p. 119, 1991 (in Japanese).

Utada, H., Y. Sasai, I. Nakagawa, S. Koyama, Y. Ishikawa, and Y. Hamano, Changes in the electrical resistivity associated with the 1983 eruption of Miyake-jima volcano, Bull. Volcanol. Soc. Japan, Ser. 2, 29, S113-S124, 1984 (in Japanese with English abstract).

Utada, H., Y. Sasai, T. Shimomura, T. Yukutake, and T, Yamamoto, Changes in the resistivity for the two years after the 1983 eruption of Miyake-jima volcano, Report of the Second Joint Geophysical and Geochemical Observations of Miyake-jima Volcano (1985), 35-46, 1986 (in Japanese).

Uyeshima, M., H. Utada, and Y. Nishida, The network MT method and its first results in the eastern part of Hokkaido, NE Japan, Phys. Earth Planet. Inter., 1997 (submitted).

Yamamoto, T., A. Yamazaki, M. Churei, Y. Sasai, H. Utada, T. Kawase, and I. Nakagawa, Repetition survey of geomagnetic total intensity in Miyake-jima, Proc. CA Symposium (1993), 195-205, 1993 (in Japanese).

Yukutake, T., An overview of the eruptions of Oshima Volcano, Izu, 1986-1987, from the geomagnetic and geo- 
electric standpoints, J. Geomag. Geoelectr., 42, 141-150, 1990.

Yukutake, T., M. Sawada, T. Yabu, S. Uyeda, and K. Horai, Investigation of magnetic changes in the 1983 eruption of Miyake-jima volcano, Bull. Volcanol. Soc. Japan, 8, 50, 1963 (in Japanese).

Yukutake, T., T. Yoshino, H. Utada, M. Kawamura, K. Ohchi, T. Koike, O. A. Veliz-Castillo, Y. Tanaka, and M. Mishina, Resistivity survey on Miyake-jima volcano, Report of the First Joint Geophysical Observations on Miyake-jima Volcano (1980), 43-53, 1982 (in Japanese).

Yukutake, T., T. Yoshino, H. Utada, H. Watanabe, Y. Hamano, Y. Sasai, and T. Shimomura, Changes in the electrical resistivity of the central cone, Miharayama, of Izu-Oshima volcano, associated with its eruption in November, 1986, Proc. Japan Acad., 63-B, 55-58, 1987.

Zablocki, C. J., Mapping thermal anomalies on an active volcano by the Self-Potential method, Kilanea, Hawaii, Proc. 2nd U.N. Symposium on the Development and Use of Geothermal Ressources, San Francisco, 1975, 2, 1,299-1,309, 1976.

Zlotnicki, J. and J. L. Le Mouel, Volcanomagnetic effects observed on Piton de la Fournaise volcano (Reunion Island): 1985-1987, J. Geophys. Res., 93, 9157-9171, 1988.

Zlotnicki, J. and J. L. Le Mouel, Possible electrokinetic origin of large magnetic variations at La Fournaise volcano, Nature, 343, 633-636, 1990.

Zlotnicki, J., J. L. Le Mouel, J. C. Delmond, C. Pambrun, and H. Delorme, Magnetic variations on Piton de la Fournaise volcano. Volcanomagnetic signals associated with the November 6 and 30, 1987, eruptions, J. Volcanol. Geotherm. Res., 56, 281-296, 1993.

Zlotnicki, J., M. Feuillard, and G. Hammouya, Water circulations on la Soufriere volcano (Guadeloupe, Lesser Antilles): May-December 1992 seismovolcanic crisis. Renew of volcanic activity ?, J. Geomag. Geoelectr., 46, $797-813,1994 a$.

Zlotnicki, J., S. Michel, and C. Annen, Self-potential anomalies and convective systems on la Fournaise volcano (Reunion island, France), C. R. Acad. Sci. Paris, 318, Ser. II, 1,325-1,331, 1994b (in French with extended English abstract).

Zlotnicki, J., J. L. Le Mouel, S. Michel, P. Yvetot, and L. Perdereau, Slow magnetic and Self Potential variations on la Fournaise volcano (Reunion Island), 13th Workshop on the Electromagnetic Induction in the Earth, Hokkaido, Japan, July, 1996. 